\title{
Halogen Bonding Facilitates Intersystem Crossing in Iodo-BODIPY Chromophores
}

\author{
Yumin Lee $^{1}$, Roy M. Malamakal ${ }^{1}$, David M. Chenoweth ${ }^{1}$ and Jessica M. Anna ${ }^{1 *}$ \\ University of Pennsylvania, 231 South 34 Street, Philadelphia, Pennsylvania 19104, United States. \\ *E-mail : jmanna@sas.upenn.edu
}

\section{Supporting Information}

\section{Table of Contents}

I. Experimental Details for Steady State and Ultrafast Spectroscopy $\ldots \ldots \ldots \ldots \ldots \ldots \ldots \ldots . \quad$ S2

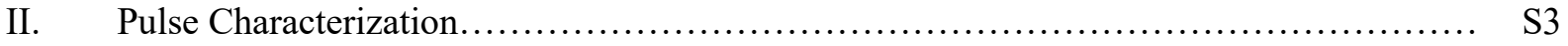

III. UV/VIS and Fluorescence Spectra of BODIPY-2I................................ S4

IV. Evidence of Halogen Bond Formation.......................................... S4

V. Calculated Electrostatic Potential Maps and Molecular Orbitals ........................ S6

VI. Solvent Dependent Transient Absorption Spectra of BODIPY-2I................... S8

VII. Singular Value Decomposition (SVD) of Transient Absorption Spectra.................. S10

VIII. Global and Target Analysis.............................................. S12

IX. DFT, TD-DFT, and Spin-Orbit Coupling Calculations............................ S18

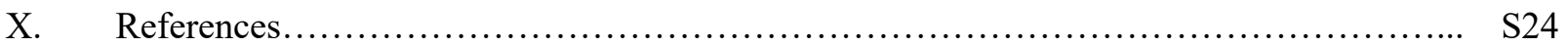




\section{Experimental Details for Steady State and Ultrafast Spectroscopy}

\section{I-(i) Sample Preparation and Steady State Spectroscopy}

BODIPY-2I and BODIPY-2H were synthesized according to a previous protocol by Lim and coworkers. ${ }^{1}$ A detailed characterization of the BODIPY derivatives by HPLC, steady-state UV/VIS, and fluorescence spectroscopy was reported in our previous paper. ${ }^{2}$ Ultrafast transient absorption spectroscopy (see SI section I-(ii) for details) was performed on BODIPY-2I and BODIPY-2H dissolved in solutions of $0.5 \mathrm{M}$ methanol, pyridine, 2,6-dimethylpyridine (DMP), and 4-dimethylaminopyridine (DMAP) in tetrahydrofuran (THF). The ultrafast measurements were performed on samples having an optical density of $\sim 0.3$ at the wavelength corresponding to the maximum absorption of the $\mathrm{S}_{1}$ transition of BODIPY in a quartz cuvette having a pathlength of $1 \mathrm{~mm}$ (Starna, 21-Q-1). This corresponds to a concentration of 33.1 $\pm 0.7 \mu \mathrm{M}$ of the BODIPY chromophores determined using the extinction coefficient of BODIPY-2I of $\varepsilon=$ $93000 \mathrm{M}^{-1} \mathrm{~cm}^{-1}$ taken from previous literature ${ }^{1}$. Linear UV/VIS spectra were measured with a JASCO V750 spectrometer before and after the ultrafast measurements to ensure the sample integrity. Fluorescence spectra were measured with a HORIBA FL1039/40 fluorometer using a Starna quartz cuvette (Starna, 16.12F-Q-1.5) with a pathlength of $1.5 \mathrm{~mm}$. All spectroscopic results were collected at room temperature.

\section{I-(ii) Ultrafast Transient Absorption Spectroscopy}

A schematic of our experimental setup for the transient absorption spectrometer is shown in Fig. S1. To obtain transient absorption spectra, the pump and probe pulses are generated from the output of a commercial Ti:Sapphire laser ( $800 \mathrm{~nm}, \sim 100$ fs pulses, repetition rate of $1 \mathrm{kHz}$, Coherent Libra, $4 \mathrm{~W}$ ). A portion of the $800 \mathrm{~nm}$ output is directed towards a home-built NOPA to generate the pump pulses. The NOPA output is spectrally tuned to overlap with the $\mathrm{S}_{1}$ transition of the BODIPY chromophores. The spectrum of the pump pulse is plotted as a green shaded area in Fig. S3 along with the absorption and fluorescence spectra of BODIPY-2I in the different solvents. The NOPA output was compressed to $36 \mathrm{fs}$ with a single grating and a single prism compressor ${ }^{3}$ and characterized by second harmonic generation frequency resolved optical gating (SHG-FROG) ${ }^{4}$ with a $100 \mu \mathrm{m}$ BBO crystal (see Fig. S2). The probe pulses are generated by focusing a portion of the $800 \mathrm{~nm}$ laser output into a $3 \mathrm{~mm}$ thick c-cut Sapphire crystal to generate a white-light continuum. The white-light continuum spans a spectral range from 450$750 \mathrm{~nm}$. The spectrum of the probe pulse is also plotted in Fig. S3 as a pink shaded area. The white-light continuum was compressed with an isosceles prism pair ${ }^{5}$ by using the spectral fringes between the scatter of the pump and probe pulses after passing through a $25 \mu \mathrm{m}$ pinhole as a reporter for the temporal width.

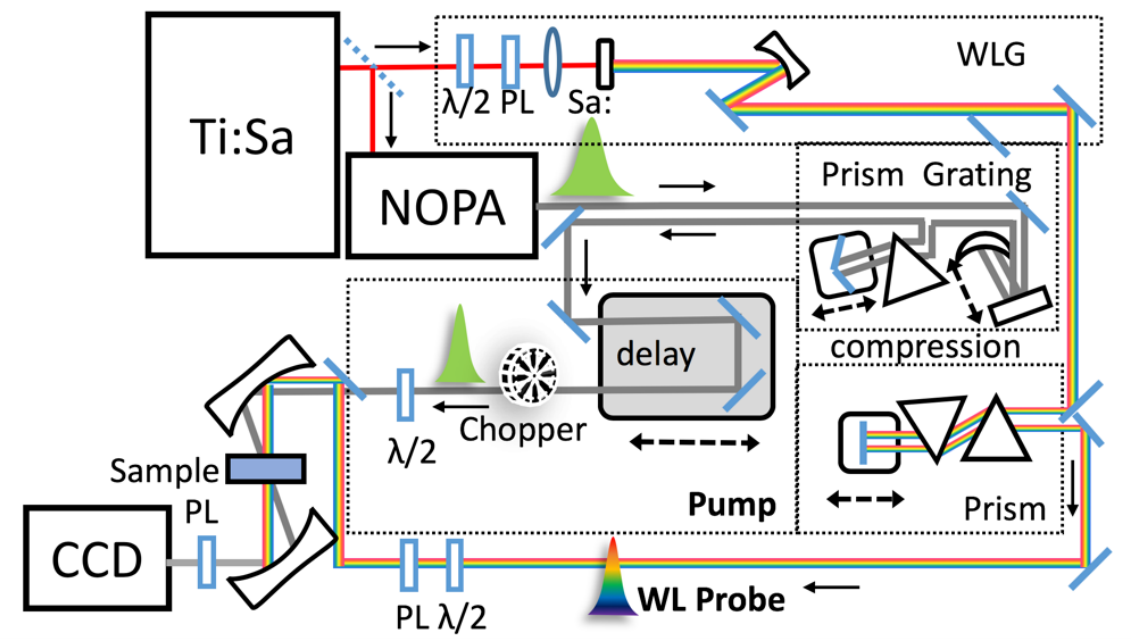

Figure S1. A schematic representation of the experimental setup of our transient absorption spectrometer. 
The transient absorption spectra were obtained with pump powers of $\sim 35 \mathrm{~nJ}$ and probe powers of $\sim 0.5 \mathrm{~nJ}$. The waiting time between the pump and probe pulses was scanned from -10 ps to $1.2 \mathrm{~ns}$ in 1 ps time steps with a computer-controlled translation stage (Newport ILS250cc, XPS Q8). The step size of 1 ps was chosen to characterize ISC that occurs on the $150-300 \mathrm{ps}$ timescale. We note that this step size does not resolve the initial femtosecond dynamics. A detailed characterization of the ultrafast solvation dynamics and vibrational coherences of the iodo-BODIPY chromophore is provided in our previous work. ${ }^{2}$ For each waiting time, every other pump pulse was blocked by a mechanical chopper operating at $500 \mathrm{~Hz}$. The probe pulse with the pump on and off was spectrally resolved with a spectrometer (Andor Shamrock 500i) and the spectra were collected by a CCD camera (Andor Newton EMCCD: DU970P-FI). For each waiting time 1000 probe spectra were collected (500 pump on, 500 pump off pairs). The transient absorption spectra reported are from the average of 500 pump on, pump off pairs collected at a given waiting time. All the transient absorption measurements were performed with pulses set to the magic angle polarization, $54.7^{\circ}$. The spectra were analyzed through a global and target analysis performed by code written in MATLAB. All transient absorption spectra were obtained in triplicate in order to confirm reproducibility. Error bars are reported based on analysis of all collected data sets.

\section{Pulse Characterization}

The incoming pump pulse was characterized by second harmonic generation frequency resolved optical gating (SHG-FROG) using a $100 \mu \mathrm{m} \mathrm{BBO}$ crystal as a nonlinear medium. ${ }^{4}$ The autocorrelation of the pump pulse is shown in Fig. S2. According to SHG-FROG, the NOPA pump pulses have a full width at half maximum (FWHM) of $36 \mathrm{fs}$.

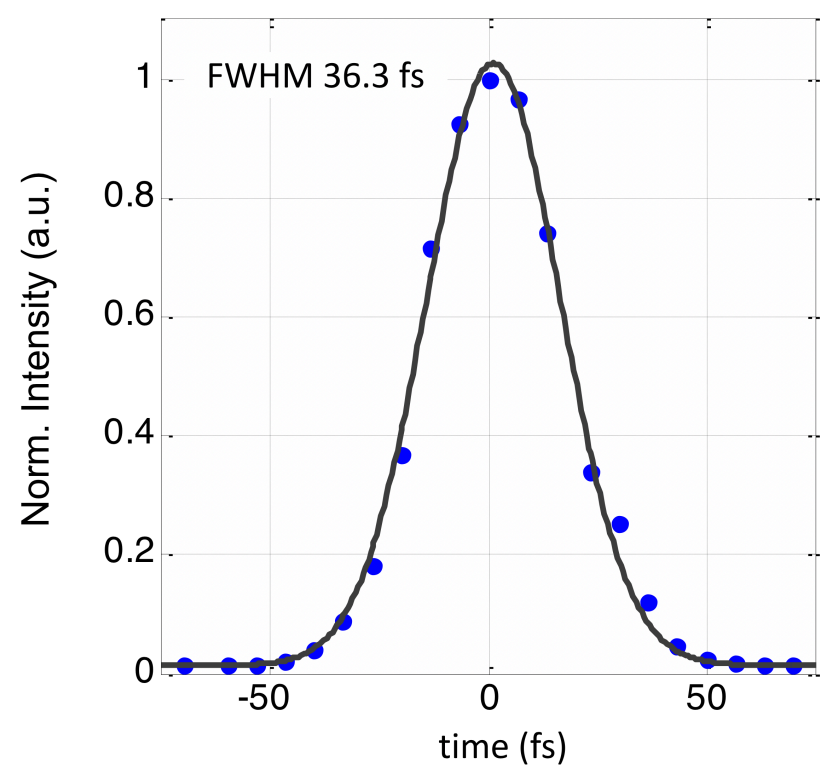

Figure S2. The plot of the SHG-FROG of the pump pulse along the time axis. 


\section{UV/VIS and Fluorescence Spectra of BODIPY-2I}

The normalized linear UV/VIS spectra (solid lines) and fluorescence spectra (dashed lines) of $33.1 \pm 0.7$ $\mu \mathrm{M}$ BODIPY-2I in the different $0.5 \mathrm{M}$ solutions of methanol (yellow), pyridine (blue), DMP (green), and DMAP (orange) in THF are shown in Fig. S3. Given the concentrations, there are more XB acceptor molecules than BODIPY chromophores, with a ratio of $\sim 15000 \mathrm{XB}$ acceptors to 1 BODIPY chromophore. The spectra of the pump (green shaded area) and probe (pink shaded area) pulses used in the transient absorption measurements are also plotted in Fig. S3. The transient absorption spectra are presented in Fig. 2 and Fig. 4 of the main text. We note that we have performed additional transient absorption measurements confirming that increasing the concentration of the XB acceptor results in a further decrease in the timescale for ISC. However, though a larger effect can be observed with an increased XB acceptor concentration, a concentration of $0.5 \mathrm{M}$ for the $\mathrm{XB}$ acceptor was used to ensure minimal frequency shifts to the linear spectra that may result from changes in the dielectric constant of the solvent.

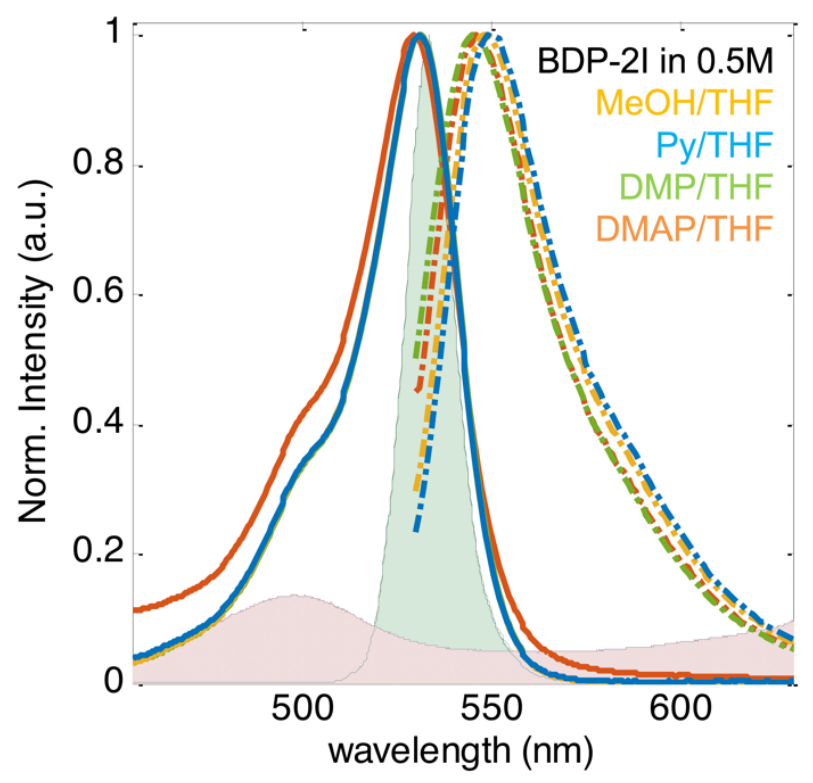

Figure S3. The linear UV/VIS (solid lines) and fluorescence spectra (dashed lines) of BODIPY-2I in different solutions: $0.5 \mathrm{M}$ of methanol (yellow), pyridine (blue), DMP (green), DMAP (orange) in THF. The spectra of the pump pulse (green shaded area) and probe pulse (pink shaded area) are also plotted.

\section{Evidence of Halogen Bond Formation}

To confirm the formation of halogen bonds, we compare the spectral broadening of the transitions in the UV/VIS spectra of BODIPY-2I in the different solutions to that of BODIPY-2H, our nonhalogen bonding control. Here we interpret the observation of spectral broadening as evidence of halogen bond formation, similar to spectral broadening arising from hydrogen bonding. ${ }^{6}$ 
The UV/VIS spectra of BODIPY-2I and BODPIPY-2H in the different solutions are shown in Fig. S4 along with Gaussian components resulting in the best fits. The UV/VIS spectra of BODIPY-2I could be fit well with two Gaussian components, while the UV/VIS spectra of BODIPY-2H required three Gaussian components. The optimized parameters are reported in Table S1 for both systems.

Halogen bonding is similar to hydrogen bonding, both being directional and dynamic in room temperature solvents, with typical energies of a few kcals $/ \mathrm{mol} .{ }^{6}$ Given these similarities we expect halogen bonding to lead to the spectral broadening of transitions, similar to spectral broadening arising from the inhomogeneity induced by hydrogen bonding solvents. Comparing the spectral width of BODIPY-2I in the different pyridine-based solutions to that of $\mathrm{MeOH}$, we find that the $\mathrm{XB}$ solutions act to increase the spectral broadening, with the total change in the FWHM ( $\left.\Delta_{\text {FWHM,Total }}\right)$ of the peaks being largest for DMAP at $\Delta_{\text {FWHM,Total }}=9.2 \mathrm{THz}$, followed by pyridine, with $\Delta_{\text {FWHM,Total }}=0.5 \mathrm{THz}$, and DMP with $\Delta_{\text {FWHM,Total }}=0.3 \mathrm{THz}$ (see Table S1). The observed increase in spectral broadening is attributed to an increase in the inhomogeneity arising from halogen bond formation.
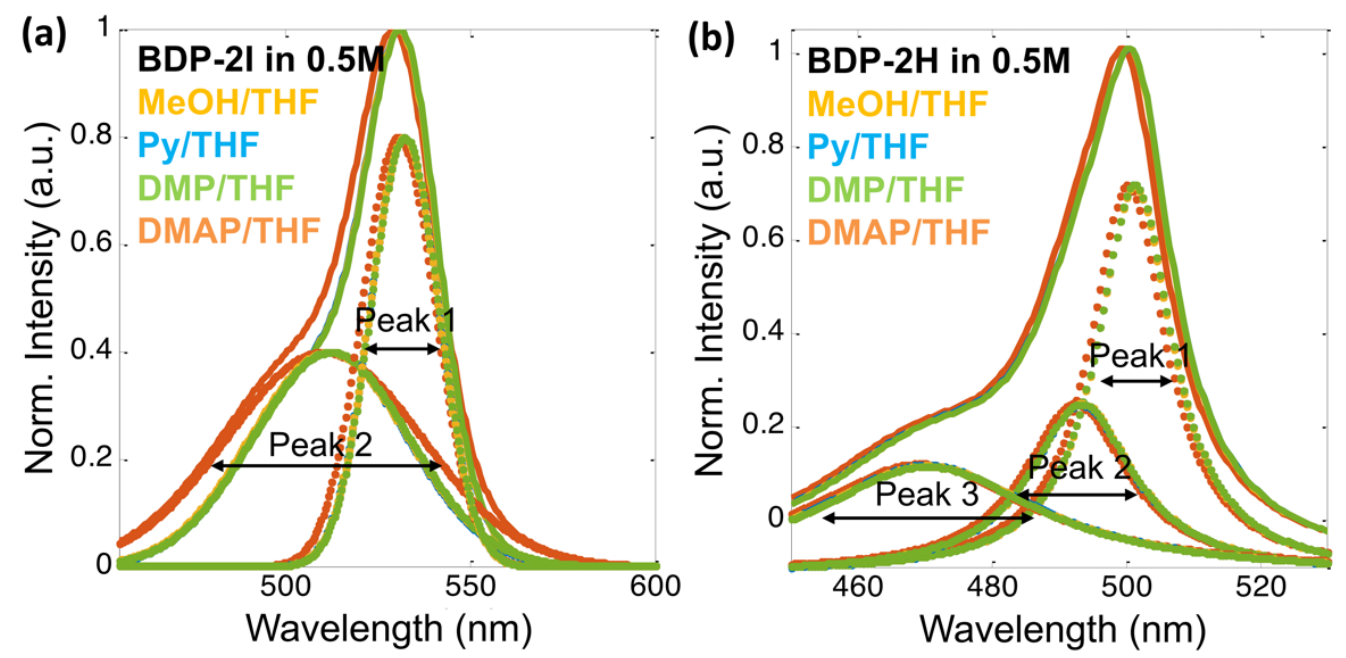

Figure S4. The Gaussian decomposition of the normalized UV/VIS spectra of BODIPY-2I (a) and BODIPY-2H (b) in the different solutions: methanol (yellow), pyridine (blue), DMP (green), and DMAP (orange) at $0.5 \mathrm{M}$ in THF.

As a control experiment, we performed the same analysis on BODIPY-2H in the same solvent series to rule out other line broadening mechanisms that may arise from changing the solvents. As BODIPY-2H lacks halogens it does not have the ability to form halogen bonds. Analysis of the total peak broadening of BODIPY-2H in the different pyridine-based solutions shows that the peak widths slightly decrease in all of the pyridine-based solutions when compared to the MeOH/THF solution. This slight decrease is attributed to the lack of hydrogen bonding between the carboxylic acid group and the pyridine-based solutions. These control measurements offer further support that the line-broadening observed in BODIPY-2I solutions arises from halogen bonding. 
Table S1. Gaussian decomposition of the UV/VIS spectra and analysis of line-broadening results for BODIPY-2I and BODIPY-2H in the different solutions with each halogen bond acceptor and the $\mathrm{MeOH}$ control solvent at a concentration of $0.5 \mathrm{M}$ in THF.

\begin{tabular}{|c|c|c|c|c|c|c|c|c|c|c|}
\hline \multirow[t]{2}{*}{ Solution } & \multicolumn{3}{|c|}{$\begin{array}{c}\text { Maximum Peak position } \\
v_{\text {max,peak }}(\mathrm{THz})\end{array}$} & \multicolumn{3}{|c|}{$\begin{array}{c}\text { FWHM } \\
(\mathrm{THz})\end{array}$} & \multicolumn{3}{|c|}{$\begin{array}{c}\Delta \mathrm{FWHM} \\
\text { with respect to } \mathrm{MeOH} \\
(\mathrm{THz})\end{array}$} & \multirow{2}{*}{$\begin{array}{c}\text { Total } \\
\Delta \text { FWHM } \\
(\Delta \text { FWHM,Total }) \\
(\mathrm{THz})\end{array}$} \\
\hline & Peak 1 & Peak 2 & Peak 3 & Peak 1 & Peak 2 & Peak 3 & Peak 1 & Peak 2 & Peak 3 & \\
\hline \multicolumn{11}{|c|}{ BODIPY-2I } \\
\hline $\mathrm{MeOH}$ & 563.7 & 585.8 & - & 14.3 & 32.4 & - & - & - & - & - \\
\hline pyridine & 563.7 & 586.0 & - & 14.3 & 32.9 & - & 0.0 & 0.5 & - & 0.5 \\
\hline DMP & 563.4 & 585.4 & - & 14.3 & 32.7 & - & 0.0 & 0.3 & - & 0.3 \\
\hline DMAP & 565.3 & 587.5 & - & 15.3 & 40.6 & - & 1.0 & 8.2 & - & 9.2 \\
\hline \multicolumn{11}{|c|}{ BODIPY-2H } \\
\hline $\mathrm{MeOH}$ & 598.2 & 607.8 & 637.6 & 13.9 & 8.3 & 11.7 & - & - & - & - \\
\hline pyridine & 598.2 & 607.8 & 637.6 & 13.8 & 8.4 & 11.6 & -0.1 & 0.1 & -0.1 & -0.1 \\
\hline DMP & 598.1 & 607.8 & 637.5 & 13.9 & 8.4 & 11.5 & 0.0 & 0.1 & -0.2 & -0.1 \\
\hline DMAP & 599.4 & 609.0 & 639.0 & 13.9 & 8.3 & 11.6 & 0.0 & 0 & -0.1 & -0.1 \\
\hline
\end{tabular}

\section{Calculated Electrostatic Potential Maps and Molecular Orbitals}

\section{Electrostatic Potential Maps}

The electrostatic potential maps presented in Figure 1 of the main text were generated from optimized geometries of BODIPY-2I, BODIPY-2H and the XB acceptors obtained using the Guassian09 software package. ${ }^{7}$ The optimized geometries for BODIPY-2I and BODIPY-2H were taken from our previous publication ${ }^{2}$ and the electrostatic potential maps were generated using the same basis sets as reported previously. For the pyridine-based XB acceptors DFT calculations were performed at the B3LYP level of theory with the $6-311++\mathrm{g}(\mathrm{d}, \mathrm{p})$ basis set to first determine the optimized geometries and then generate the electrostatic potential maps presented in Fig. 1 of the main text.

\section{Molecular Orbitals}

We have compared the molecular orbitals associated with vertical transitions for non-XB BODIPY-2I to those of the halogen bonded BODIPY-2I to determine if the presence of the XB acceptors alters the character of the vertical transition. TD-DFT calculations were performed (see section IX of the SI) to determine which molecular orbitals contribute to the $\mathrm{S}_{0}$-to- $\mathrm{S}_{1}$ transition. 
The molecular orbitals involved in the $\mathrm{S}_{1}$ vertical transition are reported in Table $\mathrm{S} 2$ for non-XB BODIPY-2I and XB BODIPY-2I and the relevant molecular orbitals are plotted in Fig. S5. Comparison of the molecular orbitals confirms that excitation to the $S_{1}$ state involves similar $\pi-\pi^{*}$ transitions localized on the BODIPY core. We note that the relevant molecular orbitals have little to no electron density on the XB acceptors and that the transitions occur at energies similar to nonXB BODIPY-2I. Comparison of the molecular orbitals indicates that the vertical transitions do not have significant charge transfer character associated with the XB acceptors. To further rule out the possibility of photoinduced electron transfer we also applied an SVD analysis to the transient absorption spectra of BODIPY in the different solvents (see section VII of the SI). The SVD indicates that photoinduced electron transfer is not prominent.
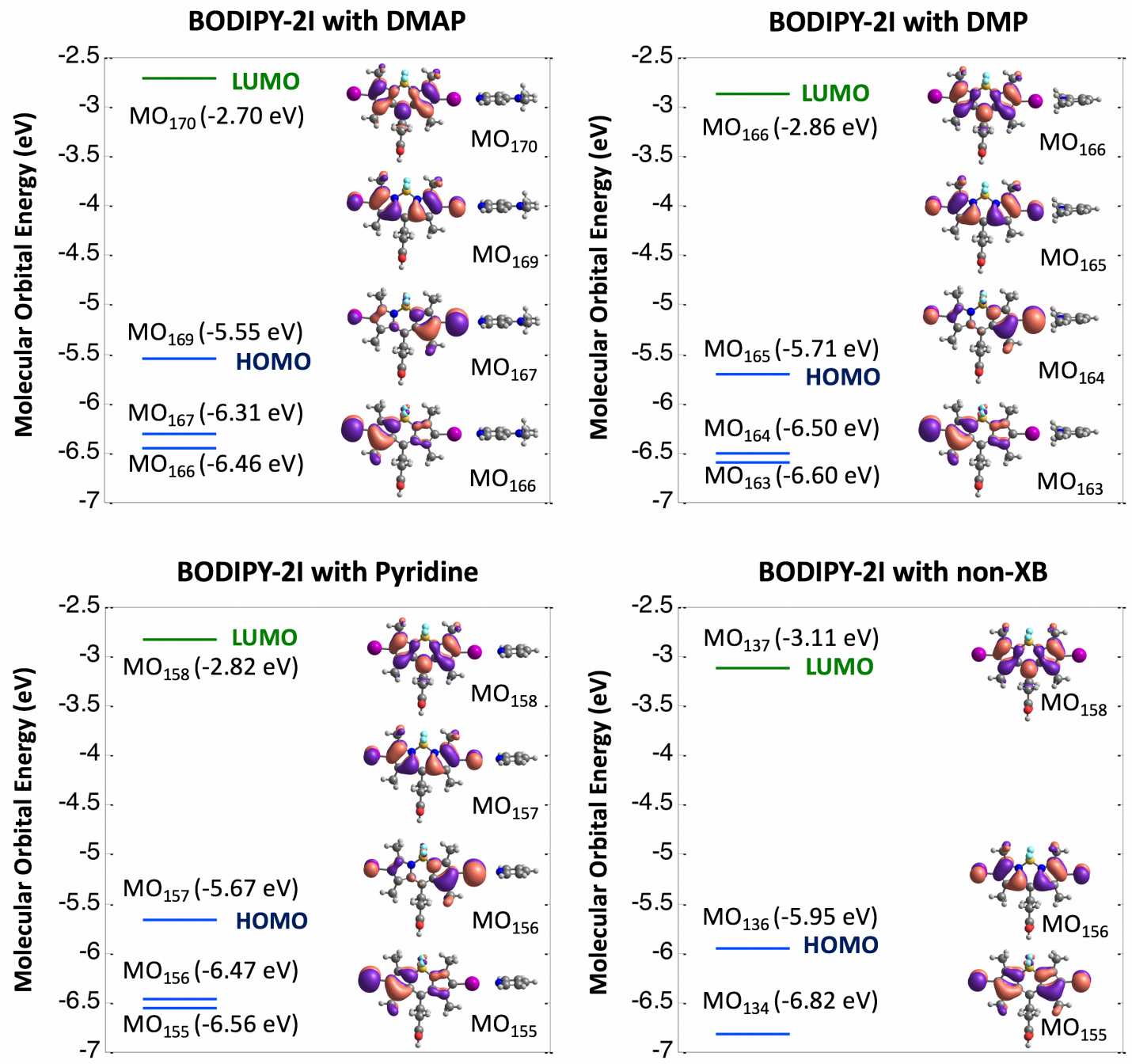

Figure S5. The calculated molecular orbitals and their energies for BODIPY-2I with XB-acceptors: DMAP, Pyridine, and DMP and without a XB-acceptor are plotted for comparison. 
Table S2. Information for the TD-DFT vertical transitions for the $S_{1}$ excited state

\begin{tabular}{|c|c|c|c|c|}
\hline \multirow[b]{2}{*}{ BODIPY-2I } & \multicolumn{4}{|c|}{$S_{1}$ Singlet Excited State } \\
\hline & Excitation from $\rightarrow$ to & Coefficients & $\begin{array}{c}\text { Excitation } \\
\text { Energy }(e V)\end{array}$ & $\begin{array}{l}\text { Oscillator } \\
\text { Strength (f) }\end{array}$ \\
\hline \multirow{3}{*}{ XB to DMAP } & MO $166 \rightarrow$ MO 170 & -0.15303 & \multirow{3}{*}{2.6989} & \multirow{3}{*}{0.5223} \\
\hline & MO $167 \rightarrow$ MO 170 & 0.20184 & & \\
\hline & MO $169 \rightarrow$ MO 170 & 0.66152 & & \\
\hline \multirow{3}{*}{ XB to DMP } & MO $163 \rightarrow$ MO 166 & -0.17016 & \multirow{3}{*}{2.7077} & \multirow{3}{*}{0.5215} \\
\hline & MO $164 \rightarrow$ MO 166 & 0.18070 & & \\
\hline & MO $165 \rightarrow$ MO 166 & 0.66375 & & \\
\hline \multirow{3}{*}{ XB to Pyridine } & MO $155 \rightarrow$ MO 158 & -0.16661 & \multirow{3}{*}{2.7126} & \multirow{3}{*}{0.5101} \\
\hline & MO $156 \rightarrow$ MO 158 & 0.18519 & & \\
\hline & MO $157 \rightarrow$ MO 158 & 0.66344 & & \\
\hline \multirow{2}{*}{ No XB } & MO $134 \rightarrow$ MO 137 & -0.24930 & \multirow{2}{*}{2.7085} & \multirow{2}{*}{0.4440} \\
\hline & MO $136 \rightarrow$ MO 137 & 0.66382 & & \\
\hline
\end{tabular}

\section{Solvent Dependent Transient Absorption Spectra of BODIPY-2I}

Transient absorption spectra of BODIPY-2I dissolved in the different XB solvents and the nonhalogen bonding control solvent are plotted in figure S6(a). The normalized time traces are plotted in Fig. S6(b) with the ground state bleach on the top, stimulated emission in the middle and excited state absorption on the bottom. The traces are color-coded according to solvent with $33.1 \pm 0.7 \mu \mathrm{M}$ BODIPY-2I in the $0.5 \mathrm{M} \mathrm{MeOH/THF}$ solution shown in yellow, $0.5 \mathrm{M}$ pyridine/THF solution shown in blue, 0.5 M DMP/THF shown in green, and 0.5 M DMAP/THF shown in orange. 

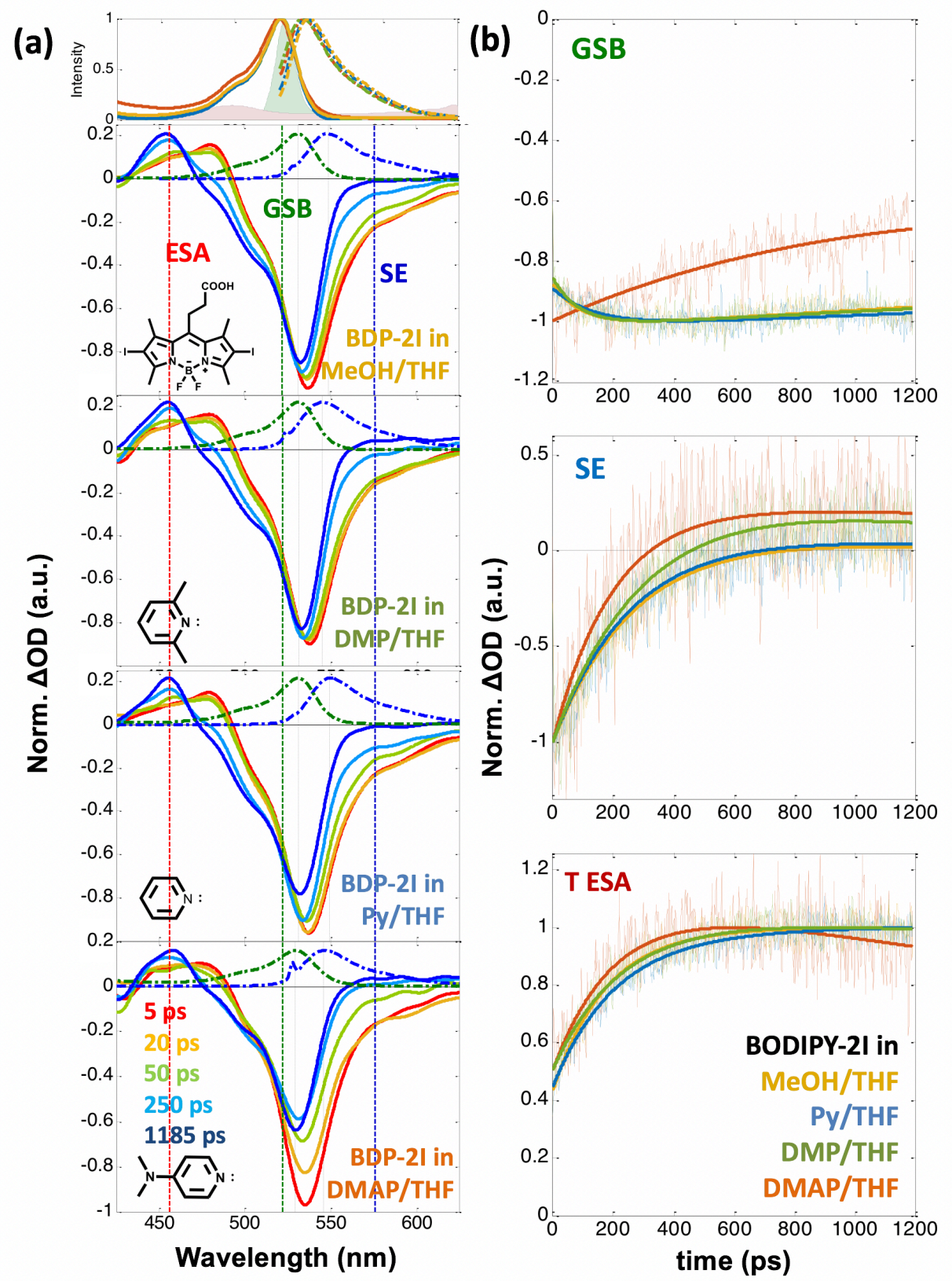

Figure S6. (a) Solvent dependent transient absorption spectra of BODIPY-2I in MeOH/THF and different XB solutions and (b) normalized time traces at wavelengths corresponding to the GSB (dashed green line, top panel), SE (dashed blue line, mid panel), and ESA (dashed red line, bottom panel).

We note that the GSB feature of DMAP taken at $\lambda=522 \mathrm{~nm}$ appears to evolve differently when compared to the GSB features of BODIPY-2I in $\mathrm{MeOH}$, pyridine and DMP taken at the same $\lambda$. This is attributed to overlapping spectral features, with the trace at $\lambda=522 \mathrm{~nm}$ for BODIPY-2I in DMAP having more contribution from the SE. To further demonstrate this we have plotted the traces of BODIPY-2I in the DMAP solution at $502 \mathrm{~nm}, 510 \mathrm{~nm}$, and $522 \mathrm{~nm}$ in Fig. S7 for comparison. We find that the trace at $510 \mathrm{~nm}$ behaves in a similar manner to that of BODIPY-2I in the other solvents, with a slight growth. We attribute this growth to overlap with ESA features. Fig. S7 demonstrates that the rate constants leading to the temporal changes in the spectra cannot 
simply be extracted from fitting the traces in the pump probe spectra to multiexponential functions. For this reason, we apply a spectro-temporal analysis to extract the rate constants associated with ISC (see section VIII).
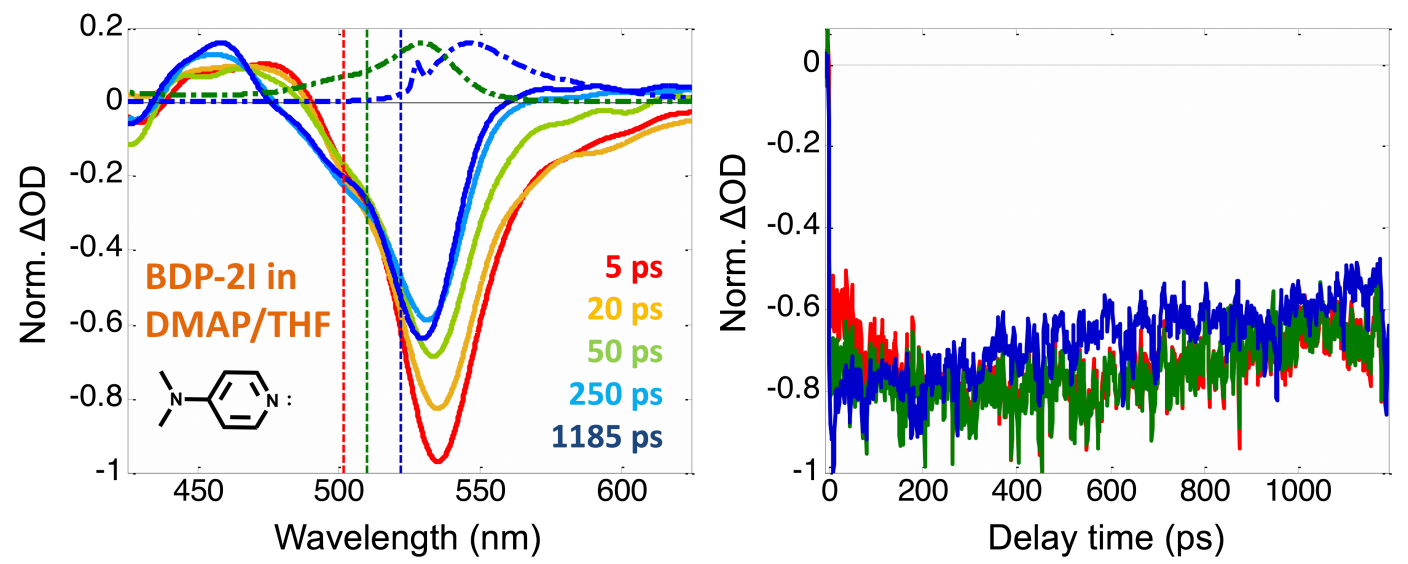

Figure S7. (a) Normalized transient absorption spectra of BODIPY-2I in 0.5M DMAP/THF and (b) the normalized time traces at wavelengths corresponding to the $\lambda=502 \mathrm{~nm}$ (dashed red line), $\lambda=510 \mathrm{~nm}$ (dashed green line), and $\lambda=522 \mathrm{~nm}$ (dashed blue line).

\section{Singular Value Decomposition (SVD) of Transient Absorption Spectra}

Applying a singular value decomposition (SVD function in MATLAB) to the transient absorption spectra we resolved 3 possible components $(n=3)$ that could contribute to the spectra of BODIPY$2 \mathrm{I}$ in the $0.5 \mathrm{M} \mathrm{XB}$ solvents and in the $0.5 \mathrm{M} \mathrm{MeOH} / \mathrm{THF}$ control solvent. The SVD decomposition of the transient absorption spectra is described by Eq. 7.1 where $\psi(\lambda, t)$ represents the transient absorption spectra. Singular values (S), spectral vectors (V), and temporal vectors (U) of BODIPY2I in 0.5 M DMAP/THF are displayed in Fig S8. We've included the first 4 spectral components, $\mathrm{V}(\mathrm{n}=1-4)$, and temporal components, $\mathrm{U}(\mathrm{n}=1-4)$, to demonstrate that the fourth component is not distinguishable from the noise. Comparing the singular values of the third and fourth component we find that the third component is larger, though the temporal vector associated with the third component suggests that the third component may not be required to describe the spectra. We confirm that the third component is not required in the DAS analysis in section VIII. An SVD analysis of BODIPY-2I in the other solutions, including the MeOH/THF control, was also performed. The results are similar to that of BODIPY-2I in 0.5M DMAP/THF and the first 3 spectral components are plotted in Fig. S9 for BODIPY-2I in each solution. The similarity in the first three spectral components of BODIPY-2I across the solvent series to that of the spectral components of BODIPY-2I in $0.5 \mathrm{M} \mathrm{MeOH} / \mathrm{THF}$ solution confirms that the pyridine-based XB solutions do not lead to additional photochemical pathways, such as photoinduced electron or hole transfer.

$$
\psi_{\text {spec }}(\lambda, t)=U S V^{T}
$$



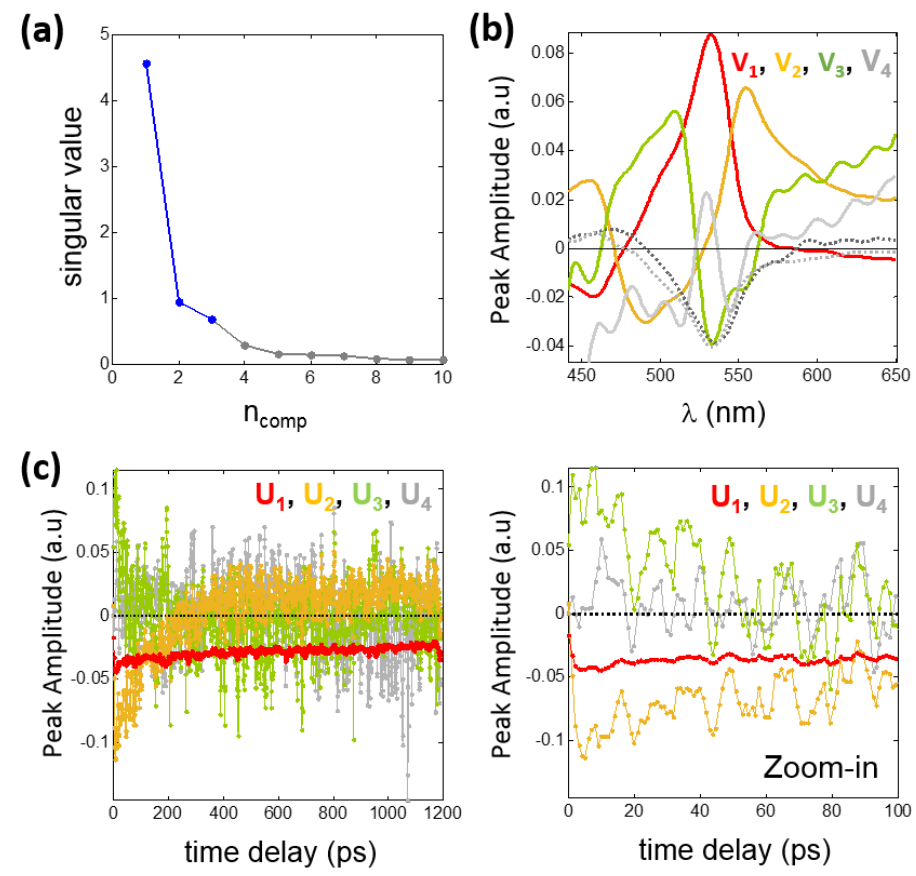

Figure S8. The results of the singular value decomposition performed on the transient absorption spectra of BODIPY2I in $0.5 \mathrm{M}$ DMAP/THF solution are presented. (a) The singular values as a function of the number of components are plotted. (b) The spectral vectors $\mathrm{V}_{\mathrm{n}}(\mathrm{n}=1 \sim 4)$ are plotted along with the early $(\mathrm{t}=1 \mathrm{ps}$, dotted dark grey line) and later $\left(t=150 \mathrm{ps}\right.$, dotted light grey line) transient absorption spectra. (c) The temporal vectors $U_{n}(n=1 \sim 4)$ are plotted from 0 to $1200 \mathrm{ps}$ (left) and from 0 to $100 \mathrm{ps}$ (right).

Spectral components $\left(V_{n=1 \sim 3}\right)$ in SVD for BODIPY-2I in different solvents
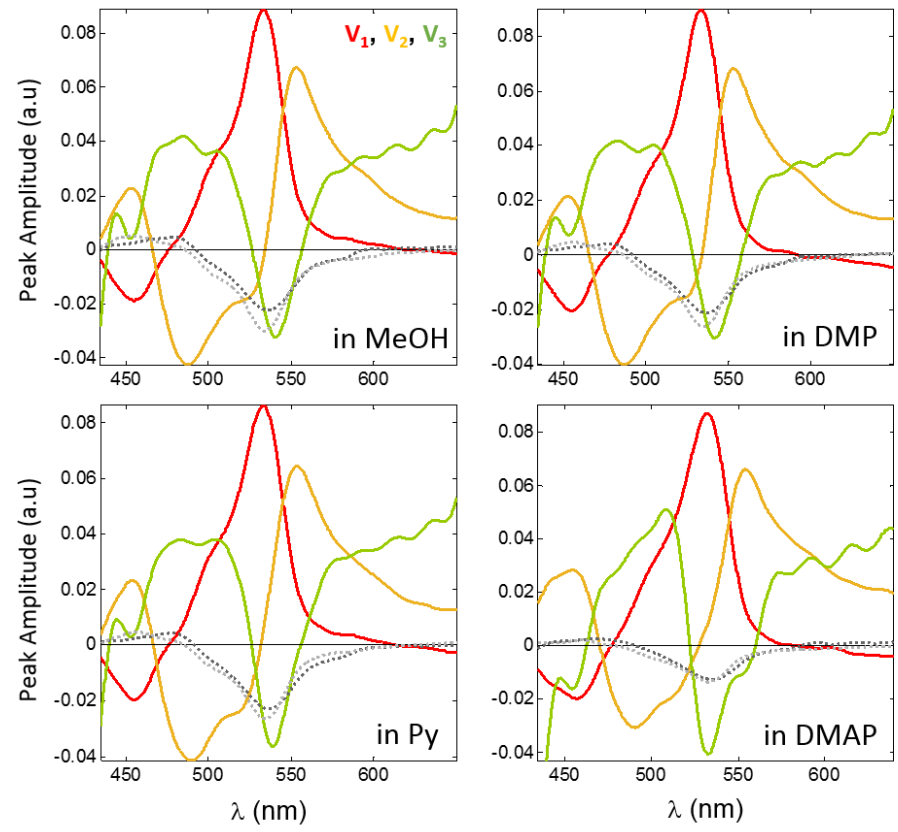

Figure S9. The results of the SVD analysis of BODIPY-2I in the different XB solutions and the methanol control solution. The spectral vectors $\mathrm{V}_{\mathrm{n}}(\mathrm{n}=1-3)$ are plotted along with the early $(\mathrm{t}=1 \mathrm{ps}$, dotted dark grey line $)$ and later $(\mathrm{t}=150 \mathrm{ps}$ dotted light grey line) transient absorption spectra. 


\section{Global and Target Analysis}

Global and target analyses are powerful tools for extracting rate constants from ultrafast transient absorption spectra. ${ }^{8}$ To extract the rate constants associated with ISC we first apply a global analysis followed by a target analysis to the transient absorption spectra of BODIPY-2I. The global and target analysis were performed in MATLAB using code written by our group. The kinetic models used for the different analyses are described in Table S3. The optimized parameters were obtained by minimizing Eq. 8.1, where $\psi_{\text {spec }}$ is the measured transient absorption spectra, $\mathrm{N}$ is the effective concentration of the components and describes how the system evolves as a function of time, and $\mathrm{E}$ is the spectra, using the lsqnonlin function in MATLAB.

$$
R=\left\|\boldsymbol{\psi}_{\text {spec }}-N E^{T}\right\|^{2}
$$

We performed two global analysis procedures, first extracting decay associated spectra (DAS), then using these time constants to extract evolutionary associated spectra (EAS) and rate constants. The results of the EAS analysis informed the spectro-temporal analysis where we extracted spectral profiles associated with the GSB, SE, and ESA. The reported rate constants are the averaged values of the extracted rate constants from three different sets of transient absorption spectra. The rate constants are reported in Table S4 along with error bars reporting on the standard error.

To extract the rate constants, we first extract decay associated spectra (DAS) and their corresponding timescales (Eq. 8.2). Based on the SVD analysis we attempted to fit the BODIPY2I data with 3 exponential decays. However, the third component was not required, and the spectra are well described with only two exponential decays. The DAS spectra $\left(A_{n}\right)$ and their corresponding exponential time decays $\left(t_{n}\right)$ for BODIPY-2I in the MeOH/THF solution are shown in Fig S10a.

$$
\psi_{\text {spec }}(\lambda, t)=\sum_{n=1}^{N_{\text {comp }}} A_{n}(\lambda) e^{-\left(t / t_{n}\right)}
$$

To interpret the DAS results, we look at the spectral position of a peak and the sign of the peak: a negative peak indicates a decay and a positive peak indicates a growth for ground state bleaches and simulated emission (negative signals), where a negative peak indicates a growth and a positive peak indicates a decay for excited state absorptions (positive signals). Looking at the first DAS component that evolves on the 237 ps timescale (blue line Fig. S10a) we observe a negative peak that aligns well with the fluorescence spectrum. This peak indicates a decay of the stimulated emission. We also observe a negative peak in the excited state absorption region at $\sim 450 \mathrm{~nm}$ indicating a growth on the same timescale. The second DAS component is associated with long timescale component (green line). The negative peak at $\sim 530 \mathrm{~nm}$ aligns well with the absorption spectra and is assigned to the long-lived ground state bleach. We also observe a positive peak in the excited state absorption region indicating that the ESA is long-lived. To summarize the DAS, the stimulated emission peak decays on a similar timescale as the growth of the excited state absorption, and that the excited state absorption and ground state bleach decay on similar timescales. This is consistent with the $\mathrm{S}_{1}$ state of BODIPY-2I undergoing intersystem crossing to the triplet state that is monitored through the ESA. The triplet state then decays back to the ground state on longer timescales. As the DAS are limited to describing sequential dynamics, we cannot interpret the timescales as rate constants; however, the DAS do offer insight into the photophysics of BODIPY-2I which can be used to inform kinetic models. 
Table S3. Global Analysis of the transient absorption spectra of BODIPY-2I and Jablonski diagram defining the rate constants and photophysical processes

\begin{tabular}{|c|c|c|c|}
\hline $\begin{array}{c}\text { Kinetic } \\
\text { Analysis }\end{array}$ & $\boldsymbol{\Psi}=\boldsymbol{N} \boldsymbol{E}^{\mathbf{T}}$ & Rate Laws & $\begin{array}{c}\text { Jablonski diagram for } \\
\text { BODIPY-2I }\end{array}$ \\
\hline $\begin{array}{c}\text { Decay } \\
\text { Associated } \\
\text { Spectra }\end{array}$ & $\Psi=N_{I} D A S^{T}$ & $\frac{d}{d t}\left[\begin{array}{l}N_{1}(t) \\
N_{2}(t)\end{array}\right]=\left[\begin{array}{cc}k_{1} & 0 \\
0 & k_{2}\end{array}\right]\left[\begin{array}{l}\exp \left(-k_{1} t\right) \\
\exp \left(-k_{2} t\right)\end{array}\right]$ & \\
\hline $\begin{array}{c}\text { Evolution } \\
\text { Associated } \\
\text { Spectra }\end{array}$ & $\Psi=N_{I I} E A S^{T}$ & $\frac{d}{d t}\left[\begin{array}{c}N_{S_{1}}(t) \\
N_{T}(t)\end{array}\right]=\left[\begin{array}{cc}k_{S 1} & 0 \\
k_{I S C} & k_{T}\end{array}\right]\left[\begin{array}{c}N_{S_{1}}(0) \\
N_{T}(0)\end{array}\right]$ & \\
where $\frac{d N}{d t}=K N, N=\exp (K t)$ & $\mathbf{S}_{0}$ & \\
\hline
\end{tabular}

Using information gained from the DAS, we perform an EAS analysis to extract the rate constants associated with intersystem crossing. The sequential two-compartmental kinetic model used in the EAS analysis is depicted in the Jablonski diagram shown in Fig. 3 of the main text and in the 4th column of Table $S 3$, where the $S_{1}$ state can undergo intersystem crossing to populate the triplet state $(\mathrm{T})$ or decay to the ground state. After intersystem crossing occurs the triplet state can then relax back to the ground state. With this kinetic model we have three rate constants, the rate constant for intersystem crossing $\left(\mathrm{k}_{\mathrm{ISC}}\right)$, the rate constant associated with the relaxation of the $\mathrm{S}_{1}$ state $\left(\mathrm{k}_{\mathrm{S} 1}\right)$, and a long time (non-decaying) component associated with the relaxation of the triplet state $\left(\mathrm{k}_{\mathrm{T}}\right)$. The rate constant matrix used to describe the temporal evolution and extract the EAS spectra is shown in Table S3. The TD-DFT calculations indicate that there are three triplet states that lie to lower energies than the $\mathrm{S}_{1}$ state. As such ISC can occur among the different triplet states represented here as $\mathrm{T}$. The EAS analysis yields $\mathrm{k}_{\mathrm{ISC}}$ and more accurate spectral components related to the population of $\mathrm{S}_{0}, \mathrm{~S}_{1}$, and T states. The result of the EAS analysis is shown in Fig. S10b. The first EAS component (blue line) indicates a decay of the stimulated emission. The second EAS component (green line) indicates a growth in the excited state absorption region at $\sim 450 \mathrm{~nm}$ that occurs on a similar timescale as the decay of the stimulated emission. From the EAS analysis we extract time constant for ISC $\left(1 / \mathrm{k}_{\text {ISC }}\right)$ of $247 \mathrm{ps}$ for BODIPY-2I in MeOH/THF. Through the EAS analysis we connect the population changes in the $\mathrm{S}_{1}$ and $\mathrm{T}$ spectral regions and extract a rate constant associated with intersystem crossing; however, to separate each spectral component (excited state absorption reporting on the population of the T state, stimulated emission reporting on the $\mathrm{S}_{1}$ state, and the ground state bleach reporting on the population of the $\mathrm{S}_{0}$ state) we employ a combined spectro-temporal model to extract the how the different spectral components evolve. From the spectro-temporal target analysis of the transient absorption spectra of BODIPY-2I, we separate the spectra associated with the different populations, where the excited state absorption at $\sim 450 \mathrm{~nm}$ reports on the population of the $\mathrm{T}$ state, the stimulated emission reports on the population of the $S_{1}$ state, and the ground state bleach reports on the population of the $S_{0}$ state. We used skewed Gaussian functions for fitting the spectra of the ground state bleach and stimulated emission and a Gaussian to describe the excited state absorption. The spectral parameters were constrained according to information from the linear spectra and to be consistent with the DAS and EAS spectra. The temporal model used is the same kinetic model used for the EAS spectra and the rate laws for the population of each state associated with a spectral feature are given by equations from 8.4 to 8.6. As shown in Table S5, we fixed the $\mathrm{k}_{\mathrm{S} 1}$ rate constant to correspond to 5 
ns based on the fluorescence lifetime of structurally similar halogen free BODIPYs ${ }^{9}$ and the decay of the triplet state, $\mathrm{k}_{\mathrm{T}}$ converged to a non-decaying component corresponding to $45 \mathrm{~s}$. All the rate constants are reported in Tables S5 (i)-(ii) of the supporting information.

$$
\begin{aligned}
& \frac{\mathrm{dN}_{T, E S A}}{\mathrm{dt}}=+k_{I S C}\left[S_{1}\right]-k_{T}[\mathrm{~T}] \\
& \frac{\mathrm{dN}_{S_{1}, S E}}{\mathrm{dt}}=-k_{I S C}\left[S_{1}\right]-k_{S 1}\left[S_{1}\right] \\
& \frac{\mathrm{dN}_{S_{0}, G S B}}{\mathrm{dt}}=-k_{S 1}\left[S_{1}\right]-k_{T}[\mathrm{~T}]
\end{aligned}
$$

The extracted spectral components for BODIPY-2I in MeOH/THF solution are shown in Fig. $\mathrm{S} 10 \mathrm{c}$. The green line corresponds to the excited state absorption, the red line to the ground state bleach and the blue line to the stimulated emission. The spectra evolve according to the kinetic equations, where the rate constants were optimized to produce the best fit. The temporal traces for each spectral feature that result from solving the rate laws in Eq. 8.4 to Eq. 8.6 are also shown in Fig. S10c. We find that the $S_{1}$ population decays on a timescale similar to the growth of the $T$ population, and that the $\mathrm{T}$ population and $\mathrm{S}_{0}$ population are long lived. From the spectro-temporal analysis we can clearly see how the different spectral features evolve in time, and also extract the rate constants associated with the different processes. As additional fitting parameters are required for this analysis, we rely on linear spectra and the results of the DAS and EAS to aid in determining the initial parameters for the fitting procedure and also for setting boundary conditions.

\begin{tabular}{|c|c|c|c|c|c|c|}
\hline \multirow[b]{2}{*}{$\begin{array}{l}\text { BODIPY } \\
-2 \mathrm{I} \text { in } \\
\text { different } \\
\text { solutions }^{\mathrm{a}}\end{array}$} & \multicolumn{6}{|c|}{ Global/Target fitting results } \\
\hline & $\begin{array}{c}\text { DAS: } \\
\tau_{\text {ISC }}(\mathrm{ps}) \\
\left(\text { error }^{\mathrm{b}}\right)\end{array}$ & $\begin{array}{c}\text { EAS: } \\
\tau_{\text {ISC }(p s)} \\
\left(\text { error }^{b}\right)\end{array}$ & $\begin{array}{c}\text { Spectral } \\
\text { Temporal: } \\
\tau_{\text {ISC }}(\mathrm{ps}) \\
\left(\text { error }^{b}\right)\end{array}$ & $\begin{array}{c}\text { DAS: } \\
\mathrm{k}_{\text {ISC }}\left(\mathrm{ps}^{-1}\right) \\
\left(\text { error }^{\mathrm{b}}\right)\end{array}$ & $\begin{array}{c}\text { EAS: } \\
\mathrm{k}_{\mathrm{ISC}}\left(\mathrm{ps}^{-1}\right) \\
\left(\text { error }^{\mathrm{b}}\right)\end{array}$ & $\begin{array}{c}\text { Spectral } \\
\text { Temporal: } \\
\mathrm{k}_{\text {ISC }}\left(\mathrm{ps}^{-1}\right) \\
\left(\text { error }^{\mathrm{b}}\right)\end{array}$ \\
\hline $\mathrm{MeOH}$ & $\begin{array}{l}236.9 \\
( \pm 9.6)\end{array}$ & $\begin{array}{l}246.7 \\
( \pm 14.3)\end{array}$ & $\begin{array}{l}246.0 \\
( \pm 15.8)\end{array}$ & $\begin{array}{l}4.23 \mathrm{E}^{-3} \\
\left( \pm 0.17 \mathrm{E}^{-3}\right)\end{array}$ & $\begin{array}{l}4.08 \mathrm{E}^{-3} \\
\left( \pm 0.25 \mathrm{E}^{-3}\right)\end{array}$ & $\begin{array}{l}4.10 \mathrm{E}^{-3} \\
\left( \pm 0.25 \mathrm{E}^{-3}\right)\end{array}$ \\
\hline Pyridine & $\begin{array}{l}228.7 \\
( \pm 5.2)\end{array}$ & $\begin{array}{l}243.1 \\
( \pm 5.4)\end{array}$ & $\begin{array}{l}223.0 \\
( \pm 28.0)\end{array}$ & $\begin{array}{l}4.38 \mathrm{E}^{-3} \\
\left( \pm 0.09 \mathrm{E}^{-3}\right)\end{array}$ & $\begin{array}{l}4.12 \mathrm{E}^{-3} \\
\left( \pm 0.09 \mathrm{E}^{-3}\right)\end{array}$ & $\begin{array}{l}4.61 \mathrm{E}^{-3} \\
\left( \pm 0.52 \mathrm{E}^{-3}\right)\end{array}$ \\
\hline DMP & $\begin{array}{l}234.5 \\
( \pm 14.2)\end{array}$ & $\begin{array}{l}248.5 \\
( \pm 15.1)\end{array}$ & $\begin{array}{l}211.0 \\
( \pm 13.9)\end{array}$ & $\begin{array}{l}4.30 \mathrm{E}^{-3} \\
\left( \pm 0.27 \mathrm{E}^{-3}\right)\end{array}$ & $\begin{array}{l}4.05 \mathrm{E}^{-3} \\
\left( \pm 0.25 \mathrm{E}^{-3}\right)\end{array}$ & $\begin{array}{l}4.79 \mathrm{E}^{-3} \\
\left( \pm 0.33 \mathrm{E}^{-3}\right)\end{array}$ \\
\hline DMAP & $\begin{array}{l}159.2 \\
( \pm 4.8)\end{array}$ & $\begin{array}{l}180.5 \\
( \pm 2.0)\end{array}$ & $\begin{array}{l}172.6 \\
( \pm 2.0)\end{array}$ & $\begin{array}{l}6.30 \mathrm{E}^{-3} \\
\left( \pm 0.19 \mathrm{E}^{-3}\right)\end{array}$ & $\begin{array}{l}5.54 \mathrm{E}^{-3} \\
\left( \pm 0.06 \mathrm{E}^{-3}\right)\end{array}$ & $\begin{array}{l}5.80 \mathrm{E}^{-3} \\
\left( \pm 0.07 \mathrm{E}^{-3}\right)\end{array}$ \\
\hline
\end{tabular}

Table S4. Rate constants for intersystem crossing and their corresponding timescales extracted from the different analysis procedures are reported for BODIPY-2I in different $0.5 \mathrm{M}$ solutions ${ }^{\mathrm{a}}$

${ }^{\mathrm{a}}$ All of the solutions are $0.5 \mathrm{M}$ in THF. The concentration of BODIPY-2I is $33.1 \pm 0.7 \mu \mathrm{M}$.

${ }^{b}$ The reported mean value of the rate constants is the average of the extracted fitting results from three data sets which were obtained with the similar experimental conditions. The reported mean error is the standard error (standard deviation/sqrt(number of data sets)) 
The spectra presented in Fig. S10 are for BODIPY-2I dissolved in $0.5 \mathrm{M} \mathrm{MeOH} / \mathrm{THF}$ solution but are representative of the spectra extracted from BODIPY-2I in the pyridine-based XB solutions, having similar spectral components, but differing in temporal components associated with intersystem crossing. As we are focusing on the rate constants for ISC in these studies, we report the extracted time scales in Table S4 of the SI. The reported rate constants and time constants were obtained from averaging the results of three different measurements. The reported timescales for ISC $\left(\tau_{\text {ISC }}\right)$ were obtained from first inverting the rate constants from the three different measurements then averaging the results. The error bars are the standard error obtained from the three data sets. For all data sets the fitting results of the spectro-temporal analysis and averaged results are reported in Table S5(i)-(ii) including all of rate constants, lifetimes, concentrations, amplitudes, and frequencies and spectral widths of the GSB, SE, ESA with mean error bars.
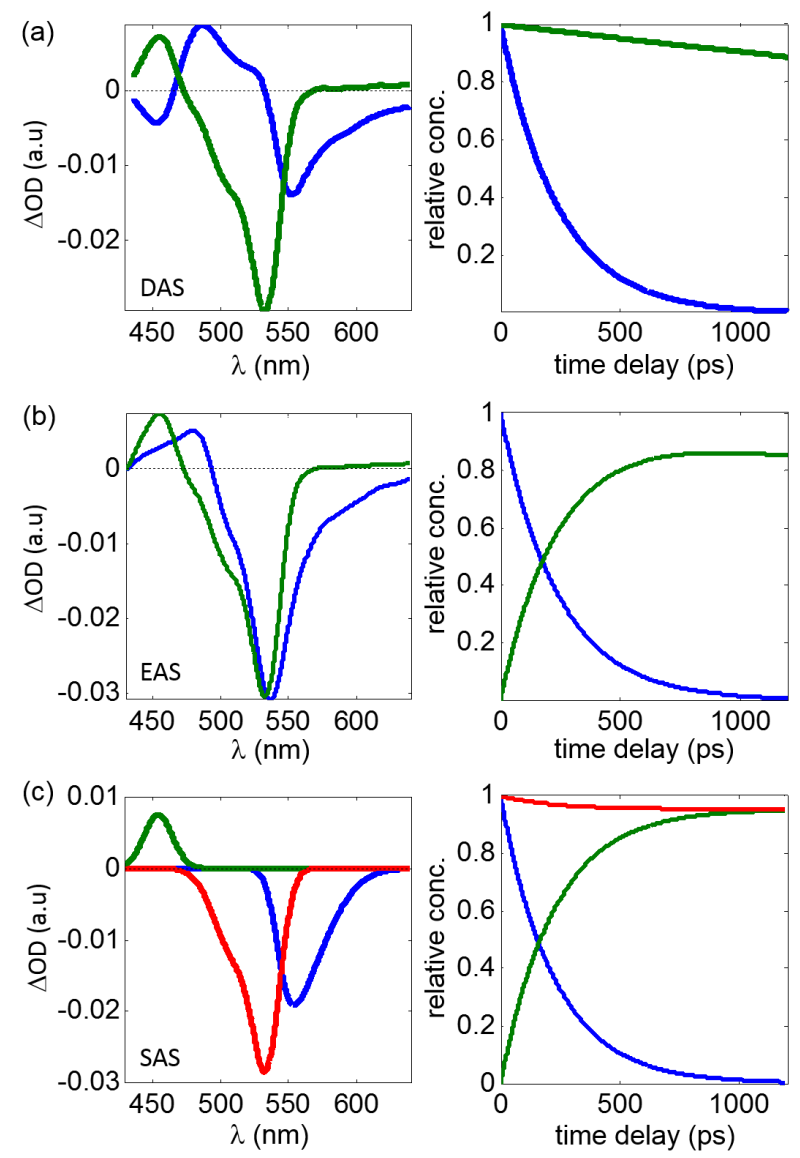

Figure S10. The results of the global and target analysis of the transient absorption spectra of BODIPY-2I in the Methanol/THF solution. The DAS spectra (a, left) and associated time trace (a, right), EAS spectra (b, left) and associated time traces (b, right) and the ESA GSB and SE spectra (c, left) with associated time traces (c, right). 
Table S5-(i). Fitting results extracted from the Spectro-Temporal analysis ${ }^{a}$

\begin{tabular}{|c|c|c|c|c|c|c|c|c|c|}
\hline \multirow{2}{*}{\multicolumn{2}{|c|}{$\begin{array}{c}\text { BODIPY-2I in } \\
\text { different } \\
\text { solutions }^{\mathrm{a}}\end{array}$}} & \multicolumn{8}{|c|}{ Target fitting (Spectro-Temporal analysis) results } \\
\hline & & \multirow{2}{*}{$\frac{\tau_{\mathrm{ISC}}(\mathrm{ps})}{234.2}$} & \multirow{2}{*}{$\begin{array}{c}\tau_{\mathrm{S} 1}(\mathrm{ps})^{\mathrm{c}} \\
\sim 5000\end{array}$} & \multirow{2}{*}{$\begin{array}{l}\tau_{\mathrm{T}}(\mathrm{s}) \\
\sim 45\end{array}$} & \multirow{2}{*}{$\frac{\mathrm{k}_{\mathrm{ISC}}\left(\mathrm{ps}^{-1}\right)}{4.27 \mathrm{E}^{-3}}$} & \multirow{2}{*}{$\frac{\mathrm{k}_{\mathrm{S} 1}\left(\mathrm{ps}^{-1}\right)^{\mathrm{c}}}{\sim 2 \mathrm{E}^{-4}}$} & \multirow{2}{*}{$\frac{\mathrm{k}_{\mathrm{T}}\left(\mathrm{ps}^{-1}\right)}{\sim 2 \mathrm{E}^{-14}}$} & \multirow{2}{*}{$\begin{array}{c}\text { Conc. SE } \\
-1.39\end{array}$} & \multirow{2}{*}{$\frac{\text { Conc. ESA }}{2.22 \mathrm{E}^{-14}}$} \\
\hline \multirow{4}{*}{$\mathrm{MeOH}$} & (i) & & & & & & & & \\
\hline & (ii) & 277.4 & $\sim 5000$ & $\sim 45$ & $3.61 \mathrm{E}^{-3}$ & $\sim 2 \mathrm{E}^{-4}$ & $\sim 2 \mathrm{E}^{-14}$ & -1.66 & $4.34 \mathrm{E}^{-14}$ \\
\hline & (iii) & 226.4 & $\sim 5000$ & $\sim 45$ & $4.42 \mathrm{E}^{-3}$ & $\sim 2 \mathrm{E}^{-4}$ & $\sim 2 \mathrm{E}^{-14}$ & -4.20 & $2.22 \mathrm{E}^{-14}$ \\
\hline & $\begin{array}{c}\text { Mean } \\
\left(\text { error }^{b}\right)\end{array}$ & $\begin{array}{c}246.0 \\
( \pm 15.8)\end{array}$ & $\sim 5000$ & $\sim 45$ & $\begin{array}{c}4.10 \mathrm{E}^{-3} \\
\left( \pm 0.25 \mathrm{E}^{-3}\right)\end{array}$ & $\sim 2 \mathrm{E}^{-4}$ & $\sim 2 \mathrm{E}^{-14}$ & $\begin{array}{c}-2.41 \\
( \pm 0.90)\end{array}$ & $\begin{array}{c}2.93 \mathrm{E}^{-14} \\
\left( \pm 7.08 \mathrm{E}^{-15}\right)\end{array}$ \\
\hline \multirow{4}{*}{ Py } & (i) & 201.2 & $\sim 5000$ & $\sim 45$ & $4.97 \mathrm{E}^{-3}$ & $\sim 2 \mathrm{E}^{-4}$ & $\sim 2 \mathrm{E}^{-14}$ & -0.91 & $2.22 \mathrm{E}^{-14}$ \\
\hline & (ii) & 189.4 & $\sim 5000$ & $\sim 45$ & $5.28 \mathrm{E}^{-3}$ & $\sim 2 \mathrm{E}^{-4}$ & $\sim 2 \mathrm{E}^{-14}$ & -0.94 & $2.22 \mathrm{E}^{-14}$ \\
\hline & (iii) & 278.5 & $\sim 5000$ & $\sim 45$ & $3.60 \mathrm{E}^{-3}$ & $\sim 2 \mathrm{E}^{-4}$ & $\sim 2 \mathrm{E}^{-14}$ & -0.57 & $3.37 \mathrm{E}^{-14}$ \\
\hline & $\begin{array}{c}\text { Mean } \\
\left(\text { error }^{b}\right)\end{array}$ & $\begin{array}{c}223.0 \\
( \pm 28.0)\end{array}$ & $\sim 5000$ & $\sim 45$ & $\begin{array}{c}4.61 \mathrm{E}^{-3} \\
\left( \pm 0.52 \mathrm{E}^{-3}\right)\end{array}$ & $\sim 2 \mathrm{E}^{-4}$ & $\sim 2 \mathrm{E}^{-14}$ & $\begin{array}{c}-0.81 \\
( \pm 0.12)\end{array}$ & $\begin{array}{c}2.60 \mathrm{E}^{-14} \\
\left( \pm 3.82 \mathrm{E}^{-15}\right)\end{array}$ \\
\hline \multirow{4}{*}{ DMP } & (i) & 185.0 & $\sim 5000$ & $\sim 45$ & $5.41 \mathrm{E}^{-3}$ & $\sim 2 \mathrm{E}^{-4}$ & $\sim 2 \mathrm{E}^{-14}$ & -0.81 & $2.22 \mathrm{E}^{-14}$ \\
\hline & (ii) & 232.8 & $\sim 5000$ & $\sim 45$ & $4.30 \mathrm{E}^{-3}$ & $\sim 2 \mathrm{E}^{-4}$ & $\sim 2 \mathrm{E}^{-14}$ & -0.85 & $2.22 \mathrm{E}^{-14}$ \\
\hline & (iii) & 214.7 & $\sim 5000$ & $\sim 45$ & $4.66 \mathrm{E}^{-3}$ & $\sim 2 \mathrm{E}^{-4}$ & $\sim 2 \mathrm{E}^{-14}$ & -0.85 & $2.25 \mathrm{E}^{-14}$ \\
\hline & $\begin{array}{c}\text { Mean } \\
\left(\text { error }^{b}\right)\end{array}$ & $\begin{array}{c}210.8 \\
( \pm 13.9)\end{array}$ & $\sim 5000$ & $\sim 45$ & $\begin{array}{c}4.79 \mathrm{E}^{-3} \\
\left( \pm 0.33 \mathrm{E}^{-3}\right)\end{array}$ & $\sim 2 \mathrm{E}^{-4}$ & $\sim 2 \mathrm{E}^{-14}$ & $\begin{array}{c}-0.84 \\
( \pm 0.01)\end{array}$ & $\begin{array}{c}2.23 \mathrm{E}^{-14} \\
\left( \pm 8.19^{\mathrm{E}-17}\right)\end{array}$ \\
\hline \multirow{4}{*}{ DMAP } & (i) & 168.6 & $\sim 5000$ & $\sim 45$ & $5.93 \mathrm{E}^{-3}$ & $\sim 2 \mathrm{E}^{-4}$ & $\sim 2 \mathrm{E}^{-14}$ & -0.92 & $2.22 \mathrm{E}^{-14}$ \\
\hline & (ii) & 173.8 & $\sim 5000$ & $\sim 45$ & $5.75 \mathrm{E}^{-3}$ & $\sim 2 \mathrm{E}^{-4}$ & $\sim 2 \mathrm{E}^{-14}$ & -0.63 & $8.06 \mathrm{E}^{-13}$ \\
\hline & (iii) & 175.2 & $\sim 5000$ & $\sim 45$ & $5.71 \mathrm{E}^{-3}$ & $\sim 2 \mathrm{E}^{-4}$ & $\sim 2 \mathrm{E}^{-14}$ & -0.72 & $2.34 \mathrm{E}^{-14}$ \\
\hline & $\begin{array}{l}\text { Mean } \\
\left(\text { error }^{b}\right)\end{array}$ & $\begin{array}{l}172.6 \\
( \pm 2.0)\end{array}$ & $\sim 5000$ & $\sim 45$ & $\begin{array}{c}5.80 \mathrm{E}^{-3} \\
\left( \pm 0.07 \mathrm{E}^{-3}\right)\end{array}$ & $\sim 2 \mathrm{E}^{-4}$ & $\sim 2 \mathrm{E}^{-14}$ & $\begin{array}{c}-0.76 \\
( \pm 0.08)\end{array}$ & $\begin{array}{c}2.84 \mathrm{E}^{-13} \\
\left( \pm 2.61 \mathrm{E}^{-13}\right)\end{array}$ \\
\hline
\end{tabular}

${ }^{\mathrm{a}}$ All of the solutions are $0.5 \mathrm{M}$ in THF. BODIPY-2I was at a concentration of $33.1 \pm 0.7 \mu \mathrm{M}$.

${ }^{b}$ The reported mean value of the rate constants is the average of the extracted fitting results from three data sets (i) (iii) which were obtained with the similar experimental conditions. The reported mean error is the standard error (standard deviation/sqrt(number of data sets))

${ }^{\mathrm{c}}$ Rate constants for the singlet lifetime $\left(\mathrm{k}_{\mathrm{S} 1}\right)$ were set as constants. 
Table S5-(ii). Fitting results extracted from the Spectro-Temporal analysis ${ }^{a}$

\begin{tabular}{|c|c|c|c|c|c|c|c|c|c|c|c|c|c|}
\hline \multirow{3}{*}{\multicolumn{2}{|c|}{$\begin{array}{c}\text { BODIPY-2I in } \\
\text { different } \\
\text { solutions }^{\mathrm{a}}\end{array}$}} & \multicolumn{12}{|c|}{ Target fitting (Spectro-Temporal analysis) results } \\
\hline & & \multirow{2}{*}{$\begin{array}{c}\lambda_{\mathrm{s} 00, \text { center }} \\
(\mathrm{nm})\end{array}$} & \multirow{2}{*}{$\begin{array}{c}\lambda_{\mathrm{s} 00, \text { width }} \\
\text { (nm) }\end{array}$} & \multirow{2}{*}{$\begin{array}{c}\lambda_{\mathrm{s} 01, \text { center }} \\
(\mathrm{nm})\end{array}$} & \multirow{2}{*}{$\begin{array}{c}\lambda_{\mathrm{s} 01, \text { width }} \\
\text { (nm) }\end{array}$} & \multirow{2}{*}{$\begin{array}{c}\lambda_{\mathrm{SE}, \mathrm{center}} \\
(\mathrm{nm})\end{array}$} & \multirow{2}{*}{$\begin{array}{c}\lambda_{\text {SE, width }} \\
\text { (nm) }\end{array}$} & \multirow{2}{*}{$\begin{array}{c}\lambda_{\text {ESA,center }} \\
(\mathrm{nm})\end{array}$} & \multirow{2}{*}{$\begin{array}{c}\lambda_{\text {ESA,width }} \\
(\mathrm{nm})\end{array}$} & \multicolumn{3}{|c|}{ Amplitude } & \multirow{2}{*}{$\begin{array}{c}\text { Skewness } \\
\alpha\end{array}$} \\
\hline & & & & & & & & & & $\operatorname{GSB}\left(E^{-2}\right)$ & $\operatorname{SE}\left(E^{-2}\right)$ & $\operatorname{ESA}\left(\mathrm{E}^{-3}\right)$ & \\
\hline \multirow{4}{*}{$\mathrm{MeOH}$} & (i) & $\sim 534$ & 14 & 511 & 21 & 542 & 40 & 454 & 15 & -2.7 & -2.4 & -8.1 & 5.2 \\
\hline & (ii) & $\sim 534$ & 13 & 513 & 25 & 542 & 40 & 453 & 15 & -3.4 & -3.0 & -11.0 & 6.9 \\
\hline & (iii) & $\sim 534$ & 15 & 520 & 33 & 542 & 40 & 464 & 22 & -2.5 & -3.5 & -6.5 & 7.8 \\
\hline & $\begin{array}{c}\text { Mean } \\
\left(\text { error }^{b}\right)\end{array}$ & $\sim 534$ & $\begin{array}{c}14 \\
( \pm 1)\end{array}$ & $\begin{array}{l}515 \\
( \pm 3)\end{array}$ & $\begin{array}{c}27 \\
( \pm 4)\end{array}$ & $\begin{array}{l}542 \\
( \pm 0)\end{array}$ & $\begin{array}{c}40 \\
( \pm 0)\end{array}$ & $\begin{array}{l}457 \\
( \pm 3)\end{array}$ & $\begin{array}{c}17 \\
( \pm 2)\end{array}$ & $\begin{array}{c}-2.9 \\
( \pm 0.3)\end{array}$ & $\begin{array}{c}-3.0 \\
( \pm 0.3)\end{array}$ & $\begin{array}{c}-8.6 \\
( \pm 1.0)\end{array}$ & $\begin{array}{c}6.6 \\
( \pm 0.7)\end{array}$ \\
\hline \multirow{4}{*}{ Py } & (i) & $\sim 534$ & 15 & 509 & 20 & 542 & 40 & 454 & 15 & 2.8 & -2.8 & -8.7 & 3.9 \\
\hline & (ii) & $\sim 534$ & 13 & 514 & 27 & 542 & 40 & 454 & 15 & 2.2 & -2.0 & -6.8 & 8.2 \\
\hline & (iii) & $\sim 534$ & 15 & 520 & 33 & 542 & 40 & 464 & 21 & 2.2 & -3.0 & -5.4 & 7.7 \\
\hline & $\begin{array}{c}\text { Mean } \\
\left(\text { error }^{b}\right)\end{array}$ & $\sim 534$ & $\begin{array}{c}14 \\
( \pm 1)\end{array}$ & $\begin{array}{l}514 \\
( \pm 3)\end{array}$ & $\begin{array}{c}27 \\
( \pm 4)\end{array}$ & $\begin{array}{l}542 \\
( \pm 0)\end{array}$ & $\begin{array}{c}40 \\
( \pm 0)\end{array}$ & $\begin{array}{l}457 \\
( \pm 3)\end{array}$ & $\begin{array}{c}17 \\
( \pm 2)\end{array}$ & $\begin{array}{c}2.4 \\
( \pm 0.2)\end{array}$ & $\begin{array}{c}-2.6 \\
( \pm 0.3)\end{array}$ & $\begin{array}{c}-7.0 \\
( \pm 1.0)\end{array}$ & $\begin{array}{c}6.6 \\
( \pm 1.4)\end{array}$ \\
\hline \multirow{4}{*}{ DMP } & (i) & $\sim 534$ & 14 & 513 & 25 & 542 & 38 & 454 & 16 & -2.2 & -2.2 & -7.3 & 6.0 \\
\hline & (ii) & $\sim 534$ & 13 & 514 & 27 & 542 & 40 & 453 & 16 & -2.1 & -2.1 & -7.1 & 6.7 \\
\hline & (iii) & $\sim 534$ & 18 & 520 & 32 & 542 & 40 & 463 & 18 & -2.6 & -4.3 & -6.0 & 10.7 \\
\hline & $\begin{array}{c}\text { Mean } \\
\left(\text { error }^{b}\right)\end{array}$ & $\sim 534$ & $\begin{array}{c}15 \\
( \pm 2)\end{array}$ & $\begin{array}{l}516 \\
( \pm 2)\end{array}$ & $\begin{array}{c}28 \\
( \pm 2)\end{array}$ & $\begin{array}{l}542 \\
( \pm 0)\end{array}$ & $\begin{array}{c}39 \\
( \pm 1)\end{array}$ & $\begin{array}{l}457 \\
( \pm 3)\end{array}$ & $\begin{array}{c}17 \\
( \pm 1)\end{array}$ & $\begin{array}{c}-2.3 \\
( \pm 0.2)\end{array}$ & $\begin{array}{c}-2.8 \\
( \pm 0.7)\end{array}$ & $\begin{array}{c}-6.8 \\
( \pm 0.4)\end{array}$ & $\begin{array}{c}7.8 \\
( \pm 1.5)\end{array}$ \\
\hline \multirow{4}{*}{ DMAP } & (i) & $\sim 534$ & 14 & 509 & 21 & 542 & 28 & 453 & 18 & -0.7 & -1.3 & -2.2 & 0.4 \\
\hline & (ii) & $\sim 534$ & 14 & 520 & 37 & 542 & 40 & 469 & 16 & -0.7 & -1.1 & -0.8 & 2.4 \\
\hline & (iii) & $\sim 534$ & 14 & 518 & 29 & 542 & 31 & 463 & 20 & -0.1 & -0.7 & -0.5 & 1.1 \\
\hline & $\begin{array}{c}\text { Mean } \\
\left(\text { errorb }^{b}\right)\end{array}$ & $\sim 534$ & $\begin{array}{c}14 \\
( \pm 0)\end{array}$ & $\begin{array}{l}516 \\
( \pm 3)\end{array}$ & $\begin{array}{c}29 \\
( \pm 5)\end{array}$ & $\begin{array}{l}542 \\
( \pm 0)\end{array}$ & $\begin{array}{c}33 \\
( \pm 4)\end{array}$ & $\begin{array}{l}462 \\
( \pm 5)\end{array}$ & $\begin{array}{c}18 \\
( \pm 1)\end{array}$ & $\begin{array}{c}-0.5 \\
( \pm 0.1)\end{array}$ & $\begin{array}{c}-1.0 \\
( \pm 0.2)\end{array}$ & $\begin{array}{c}-1.2 \\
( \pm 0.5)\end{array}$ & $\begin{array}{c}1.3 \\
( \pm 0.6)\end{array}$ \\
\hline
\end{tabular}

${ }^{\mathrm{a}}$ All of solutions are $0.5 \mathrm{M}$ in THF. BODIPY-2I was at a concentration of $33.1 \pm 0.7 \mu \mathrm{M}$.

${ }^{b}$ The reported mean value of the rate constants is the average of the extracted fitting results from three data sets (i) (iii) which were obtained with the similar experimental conditions. The reported mean error is the standard error (standard deviation/sqrt(number of data sets)) 


\section{DFT, TD-DFT, and Spin-Orbit Coupling Calculations}

\section{IX-(i). Calculation Details}

DFT calculations were performed on BODIPY-2I halogen bonded to the different pyridine-based acceptors using the Gaussian 16 software package to determine the ground state geometries. ${ }^{10}$ The calculations were performed at the B3LYP level of theory with the $6-311++\mathrm{G}(\mathrm{d}, \mathrm{p})$ basis set for BODIPY-2I, except for the iodine atoms where the $3-21 \mathrm{G}^{*}$ basis set was used. ${ }^{9}$ For comparison, the optimized structure and energetics of non-XB BODIPY-2I were taken from our previous published results. ${ }^{2}$

To ensure that the optimized structures were independent of the initial guess geometries, we tested different initial guesses where the angle between the $\pi$-conjugated ring structure of BODIPY-2I and the ring structure of the pyridine-based acceptors were varied. See Fig. S11(a) for an example input structure. In all scenarios, we find that the energy minimum corresponds to a near perpendicular arrangement of the ring structures (see Fig. S11 (b)). For all optimized structures frequency calculations were performed and no negative frequencies were observed. The coordinates for the optimized geometries are reported in the following tables in section IX-(ii).

(a) Input structure

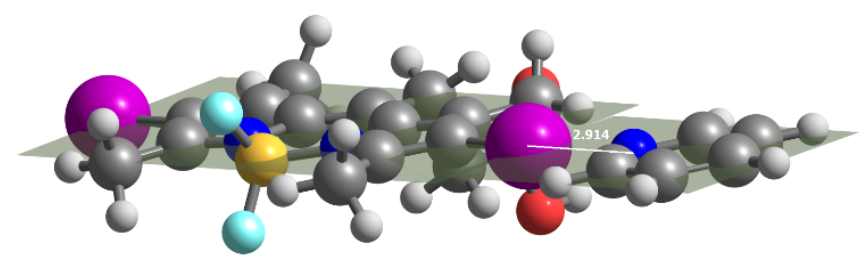

(b) Optimized structure

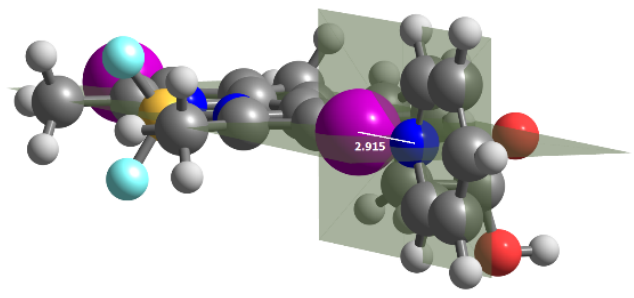

Figure S11. The input guess geometry for the DFT calculations of BODIPY-2I $\cdots$ Pyridine (a) and the resulting DFT optimized geometry of BODIPY-2I ‥Pyridine (b).

To determine the vertical transitions TD-DFT calculations were performed at the $\mathrm{S}_{0}$ optimized geometries at the B3LYP level of theory using the $6-311++\mathrm{G}(\mathrm{d}, \mathrm{p})$ basis set ${ }^{11-14}$ for all atoms. The first 5 singlet and 5 triplet states were calculated using the following keywords: TD-DFT calculation: \#P B3LYP/6-311++G(d,p) td(50-50,nstates=5) 6D 10F nosymm GFinput. The energies of the first three singlet and triplet states are reported in Table S6. The output from the TD-DFT calculations was used to obtain the spin-orbit coupling values through the PySOC program $^{15-16}$. The resulting total spin-orbit couplings between first three triplet states and singlet excited state $\left(\mathrm{V}_{\mathrm{SOC}}=<\mathrm{S}_{1}\left|\mathrm{H}_{\mathrm{SOC}}\right| \mathrm{T}_{\mathrm{n}}>, \mathrm{n}=1,2,3\right)$ are reported in Table $\mathrm{S} 6$. The calculations show that $\mathrm{XB}$ does act to alter the spin-orbit coupling for ISC among the different triplet states, but not in the same manner. 
Table S6. The energies associated with the vertical excitation energies for the first six excited states of BODIPY-2I with different XB acceptors the magnitude of the SOC from the lowest lying $S_{1}$ state to the three triplet states.

\begin{tabular}{c|cc|cc|c|cc}
\hline BODIPY-2I with & \multicolumn{2}{|c|}{$\mathrm{E}_{\mathrm{Sn}}(\mathrm{eV})$} & \multicolumn{2}{|c|}{$\mathrm{E}_{\mathrm{Tn}}(\mathrm{eV})$} & $\Delta \mathrm{E}_{(\mathrm{Tn}-\mathrm{S} 1)}(\mathrm{eV})$ & \multicolumn{2}{c}{$V_{\mathrm{S}_{1}, \mathrm{~T}_{n}}^{S O C}\left(\mathrm{~cm}^{-1}\right)$} \\
\hline \multirow{3}{*}{ Non-XB } & $\mathrm{S}_{1}$ & 2.71 & $\mathrm{~T}_{1}$ & 1.55 & -1.16 & $<\mathrm{S}_{1}\left|\mathrm{H}_{\mathrm{SOC}}\right| \mathrm{T}_{1}>$ & 9.60 \\
& $\mathrm{~S}_{2}$ & 3.22 & $\mathrm{~T}_{2}$ & 2.49 & -0.22 & $<\mathrm{S}_{1}\left|\mathrm{H}_{\mathrm{SOC}}\right| \mathrm{T}_{2}>$ & 12.55 \\
& $\mathrm{~S}_{3}$ & 3.30 & $\mathrm{~T}_{3}$ & 2.64 & -0.07 & $<\mathrm{S}_{1}\left|\mathrm{H}_{\mathrm{SOC}}\right| \mathrm{T}_{3}>$ & 1.70 \\
\hline \multirow{3}{*}{ DMAP } & $\mathrm{S}_{1}$ & 2.70 & $\mathrm{~T}_{1}$ & 1.55 & -1.15 & $<\mathrm{S}_{1}\left|\mathrm{H}_{\mathrm{SOC}}\right| \mathrm{T}_{1}>$ & 8.43 \\
& $\mathrm{~S}_{2}$ & 3.19 & $\mathrm{~T}_{2}$ & 2.45 & -0.25 & $<\mathrm{S}_{1}\left|\mathrm{H}_{\mathrm{SOC}}\right| \mathrm{T}_{2}>$ & 8.25 \\
& $\mathrm{~S}_{3}$ & 3.26 & $\mathrm{~T}_{3}$ & 2.69 & -0.01 & $<\mathrm{S}_{1}\left|\mathrm{H}_{\mathrm{SOC}}\right| \mathrm{T}_{3}>$ & 5.63 \\
\hline \multirow{3}{*}{ Pyridine } & $\mathrm{S}_{1}$ & 2.71 & $\mathrm{~T}_{1}$ & 1.55 & -1.16 & $<\mathrm{S}_{1}\left|\mathrm{H}_{\mathrm{SOC}}\right| \mathrm{T}_{1}>$ & 8.35 \\
& $\mathrm{~S}_{2}$ & 3.21 & $\mathrm{~T}_{2}$ & 2.48 & -0.23 & $<\mathrm{S}_{1}\left|\mathrm{H}_{\mathrm{SOC}}\right| \mathrm{T}_{2}>$ & 9.30 \\
& $\mathrm{~S}_{3}$ & 3.32 & $\mathrm{~T}_{3}$ & 2.67 & -0.04 & $<\mathrm{S}_{1}\left|\mathrm{H}_{\mathrm{SOC}}\right| \mathrm{T}_{3}>$ & 4.51 \\
\hline \multirow{3}{*}{ DMP } & $\mathrm{S}_{1}$ & 2.71 & $\mathrm{~T}_{1}$ & 1.55 & -1.16 & $<\mathrm{S}_{1}\left|\mathrm{H}_{\mathrm{SOC}}\right| \mathrm{T}_{1}>$ & 8.20 \\
& $\mathrm{~S}_{2}$ & 3.21 & $\mathrm{~T}_{2}$ & 2.48 & -0.23 & $<\mathrm{S}_{1}\left|\mathrm{H}_{\mathrm{SOC}}\right| \mathrm{T}_{2}>$ & 8.76 \\
& $\mathrm{~S}_{3}$ & 3.32 & $\mathrm{~T}_{3}$ & 2.63 & -0.08 & $<\mathrm{S}_{1}\left|\mathrm{H}_{\mathrm{SOC}}\right| \mathrm{T}_{3}>$ & 4.95 \\
\hline
\end{tabular}

IX-(ii). Coordinates for the Optimized Geometries of Halogen Bonded BODIPY-2I

The optimized geometries for BODIPY-2I halogen bonded to the different pyridine based acceptors are given below.

Ground state $\left(\mathrm{S}_{0}\right)$ optimized geometry for BODIPY-2I $\cdots$ Pyridine
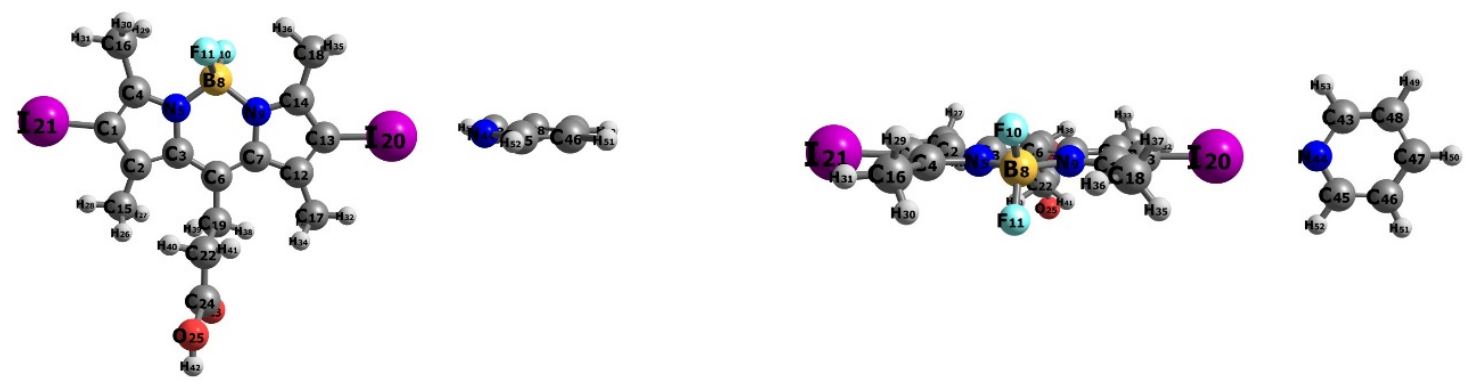

\begin{tabular}{llllrr}
$\begin{array}{l}\text { Center } \\
\text { Number }\end{array}$ & \multicolumn{2}{c}{ Atomic } & Atomic & \multicolumn{2}{c}{ Coordinates (Angstroms) } \\
- & Number & Type & X & Y & Z \\
\hline 1 & 6 & 0 & 4.648997 & -0.608303 & -0.114391 \\
2 & 6 & 0 & 3.931386 & 0.562978 & -0.360928 \\
3 & 6 & 0 & 2.553023 & 0.201792 & -0.225894 \\
4 & 6 & 0 & 3.747616 & -1.655308 & 0.163886 \\
5 & 7 & 0 & 2.499411 & -1.158162 & 0.090664 \\
6 & 6 & 0 & 1.362576 & 0.949558 & -0.359409 \\
7 & 6 & 0 & 0.107499 & 0.341421 & -0.208888
\end{tabular}




$\begin{array}{cccccc}8 & 5 & 0 & 1.208493 & -1.983105 & 0.335693 \\ 9 & 7 & 0 & 0.010897 & -1.021076 & 0.106073 \\ 10 & 9 & 0 & 1.145258 & -3.053240 & -0.567402 \\ 11 & 9 & 0 & 1.190107 & -2.468680 & 1.651990 \\ 12 & 6 & 0 & -1.233103 & 0.852820 & -0.321021 \\ 13 & 6 & 0 & -2.076802 & -0.222008 & -0.066964 \\ 14 & 6 & 0 & -1.282621 & -1.364732 & 0.195880 \\ 15 & 6 & 0 & 4.552023 & 1.879656 & -0.716895 \\ 16 & 6 & 0 & 4.033972 & -3.080442 & 0.488689 \\ 17 & 6 & 0 & -1.705640 & 2.232874 & -0.664498 \\ 18 & 6 & 0 & -1.759849 & -2.737524 & 0.521595 \\ 19 & 6 & 0 & 1.446160 & 2.434779 & -0.621301 \\ 20 & 53 & 0 & -4.187234 & -0.240173 & -0.067355 \\ 21 & 53 & 0 & 6.734238 & -0.823305 & -0.148818 \\ 22 & 6 & 0 & 1.512321 & 3.236462 & 0.689091 \\ 23 & 8 & 0 & 1.638353 & 5.273497 & -0.620591 \\ 24 & 6 & 0 & 1.606412 & 4.725951 & 0.452842 \\ 25 & 8 & 0 & 1.653622 & 5.407722 & 1.623368 \\ 26 & 1 & 0 & 4.253226 & 2.685478 & -0.043143 \\ 27 & 1 & 0 & 4.302575 & 2.188936 & -1.736547 \\ 28 & 1 & 0 & 5.637542 & 1.796163 & -0.662493 \\ 29 & 1 & 0 & 3.641168 & -3.737648 & -0.291557 \\ 30 & 1 & 0 & 3.546438 & -3.365913 & 1.423343 \\ 31 & 1 & 0 & 5.107475 & -3.238784 & 0.578674 \\ 32 & 1 & 0 & -2.793022 & 2.270271 & -0.596047 \\ 33 & 1 & 0 & -1.435019 & 2.516934 & -1.686234 \\ 34 & 1 & 0 & -1.308516 & 2.996429 & 0.008153 \\ 35 & 1 & 0 & -2.438012 & -2.701815 & 1.378873 \\ 36 & 1 & 0 & -0.936750 & -3.410628 & 0.743860 \\ 37 & 1 & 0 & -2.331867 & -3.142159 & -0.319255 \\ 38 & 1 & 0 & 0.591341 & 2.768050 & -1.200945 \\ 39 & 1 & 0 & 2.317100 & 2.665914 & -1.226551 \\ 40 & 1 & 0 & 2.370059 & 2.935471 & 1.298352 \\ 41 & 1 & 0 & 0.635959 & 3.047076 & 1.316386 \\ 42 & 1 & 0 & 1.714535 & 6.350611 & 1.406797 \\ 43 & 6 & 0 & -7.784807 & -0.553400 & -1.186019 \\ 44 & 7 & 0 & -7.101457 & -0.291432 & -0.067030 \\ 45 & 6 & 0 & -7.796683 & -0.055748 & 1.050468 \\ 46 & 6 & 0 & -9.188351 & -0.069914 & 1.099461 \\ 47 & 6 & 0 & -9.892038 & -0.342977 & -0.070367 \\ 48 & 6 & 0 & -9.175947 & -0.589894 & -1.238460 \\ 49 & 1 & 0 & -9.679917 & -0.807240 & -2.172484 \\ 50 & 1 & 0 & -10.975977 & -0.363019 & -0.071672 \\ 51 & 1 & 0 & -9.702243 & 0.127965 & 2.032410 \\ 52 & 1 & 0 & -7.211987 & 0.152670 & 1.941584 \\ 53 & 1 & 0 & -7.190658 & -0.740892 & -2.075522 \\ -----------------------------\end{array}$




\section{Ground State $\left(S_{0}\right)$ optimized geometry for BODIPY-2I $\cdots 2,6-D M P$}
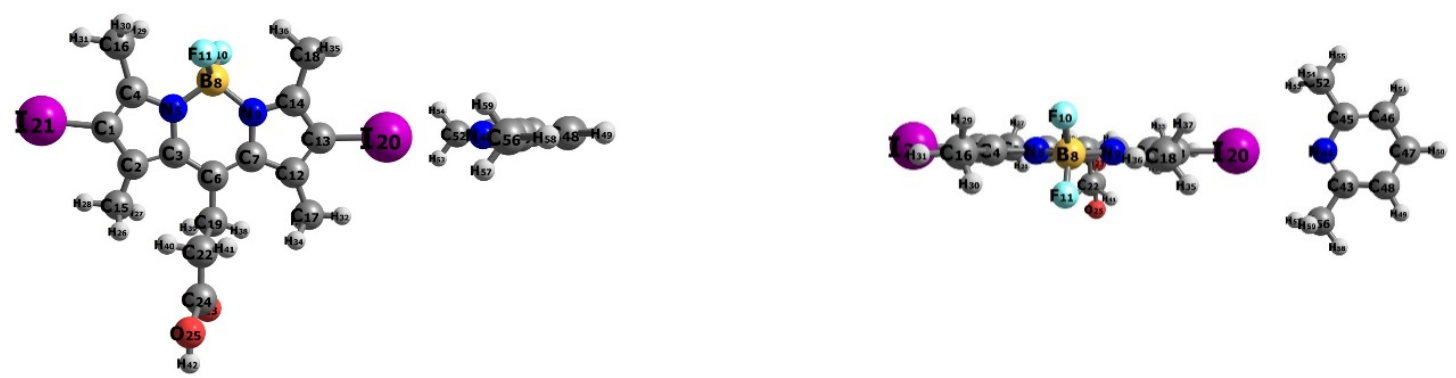

\begin{tabular}{|c|c|c|c|c|c|}
\hline \multirow{3}{*}{$\begin{array}{l}\text { Center } \\
\text { Number } \\
-1 \\
--\end{array}$} & \multirow{2}{*}{\multicolumn{2}{|c|}{$\begin{array}{l}\text { Atomic } \\
\text { Number }\end{array}$}} & \multirow{2}{*}{$\begin{array}{l}\text { Atomic } \\
\text { Type }\end{array}$} & \multicolumn{2}{|c|}{ Coordinates (Angstrom } \\
\hline & & & & X $\quad Y$ & I Z \\
\hline & 6 & 0 & 4.997736 & -0.620258 & -0.110687 \\
\hline 2 & 6 & 0 & 4.286904 & 0.553305 & -0.364427 \\
\hline 3 & 6 & 0 & 2.906195 & 0.200958 & -0.226693 \\
\hline 4 & 6 & 0 & 4.090199 & -1.660388 & 0.174694 \\
\hline 5 & 7 & 0 & 2.844961 & -1.156733 & 0.098755 \\
\hline 6 & 6 & 0 & 1.720458 & 0.954398 & -0.365043 \\
\hline 7 & 6 & 0 & 0.461469 & 0.354151 & -0.210486 \\
\hline 8 & 5 & 0 & 1.549552 & -1.972590 & 0.350167 \\
\hline 9 & 7 & 0 & 0.357222 & -1.005270 & 0.114054 \\
\hline 10 & 9 & 0 & 1.479912 & -3.048650 & -0.545179 \\
\hline 11 & 9 & 0 & 1.528248 & -2.448261 & 1.669927 \\
\hline 12 & 6 & 0 & -0.875744 & 0.872919 & -0.325727 \\
\hline 13 & 6 & 0 & -1.724965 & -0.195791 & -0.063325 \\
\hline 14 & 6 & 0 & -0.938178 & -1.341301 & 0.207375 \\
\hline 15 & 6 & 0 & 4.914814 & 1.864179 & -0.728754 \\
\hline 16 & 6 & 0 & 4.368780 & -3.085046 & 0.507976 \\
\hline 17 & 6 & 0 & -1.340281 & 2.253159 & -0.679193 \\
\hline 18 & 6 & 0 & -1.422715 & -2.709040 & 0.543658 \\
\hline 19 & 6 & 0 & 1.812045 & 2.437370 & -0.636583 \\
\hline 20 & 53 & 0 & -3.835126 & -0.202080 & -0.061452 \\
\hline 21 & 53 & & 7.081526 & -0.847844 & -0.144598 \\
\hline 22 & 6 & 0 & 1.881267 & 3.247407 & 0.668529 \\
\hline 23 & 8 & 0 & 2.002977 & 5.275433 & -0.655243 \\
\hline 24 & 6 & 0 & 1.977968 & 4.735145 & 0.422032 \\
\hline 25 & 8 & 0 & 2.035850 & 5.424130 & 1.587682 \\
\hline 26 & 1 & 0 & 4.620317 & 2.675849 & -0.060165 \\
\hline 27 & 1 & 0 & 4.667108 & 2.168189 & -1.750419 \\
\hline 28 & 1 & 0 & 5.999846 & 1.775109 & -0.673726 \\
\hline 29 & 1 & 0 & 3.981303 & -3.744033 & -0.273530 \\
\hline 30 & 1 & 0 & 3.871507 & -3.365205 & 1.439008 \\
\hline 31 & 1 & 0 & 5.440871 & -3.246669 & 0.608335 \\
\hline 32 & 1 & 0 & -2.427483 & 2.297776 & -0.612365 \\
\hline 33 & 1 & 0 & -1.066915 & 2.528746 & -1.702470 \\
\hline 34 & 1 & 0 & -0.939611 & 3.019056 & -0.011374 \\
\hline 35 & 1 & 0 & -2.087740 & -2.665607 & 1.410919 \\
\hline 36 & 1 & 0 & -0.602206 & -3.388283 & 0.756535 \\
\hline 37 & 1 & 0 & -2.009901 & -3.111461 & -0.287611 \\
\hline 38 & 1 & 0 & 0.959574 & 2.771362 & -1.219235 \\
\hline 39 & 1 & 0 & 2.684686 & 2.659944 & -1.242588 \\
\hline 40 & 1 & 0 & 2.738635 & 2.948458 & 1.279224 \\
\hline
\end{tabular}




$\begin{array}{cccccc}41 & 1 & 0 & 1.004835 & 3.064275 & 1.297657 \\ 42 & 1 & 0 & 2.097014 & 6.365575 & 1.364916 \\ 43 & 6 & 0 & -7.543502 & -0.120130 & 1.098371 \\ 44 & 7 & 0 & -6.867109 & -0.243508 & -0.055763 \\ 45 & 6 & 0 & -7.542525 & -0.397815 & -1.206812 \\ 46 & 6 & 0 & -8.939399 & -0.434215 & -1.239302 \\ 47 & 6 & 0 & -9.645377 & -0.306314 & -0.049363 \\ 48 & 6 & 0 & -8.940422 & -0.147183 & 1.137410 \\ 49 & 1 & 0 & -9.458321 & -0.044577 & 2.083423 \\ 50 & 1 & 0 & -10.729621 & -0.330825 & -0.046890 \\ 51 & 1 & 0 & -9.456496 & -0.559783 & -2.182977 \\ 52 & 6 & 0 & -6.730477 & -0.531441 & -2.468046 \\ 53 & 1 & 0 & -6.096376 & 0.347052 & -2.611664 \\ 54 & 1 & 0 & -6.065395 & -1.396588 & -2.407290 \\ 55 & 1 & 0 & -7.372811 & -0.645510 & -3.342640 \\ 56 & 6 & 0 & -6.732342 & 0.047717 & 2.356097 \\ 57 & 1 & 0 & -6.090837 & 0.929613 & 2.285175 \\ 58 & 1 & 0 & -7.375385 & 0.152172 & 3.231380 \\ 59 & 1 & 0 & -6.074608 & -0.812195 & 2.506429 \\ ------------------------------------------------------------\end{array}$

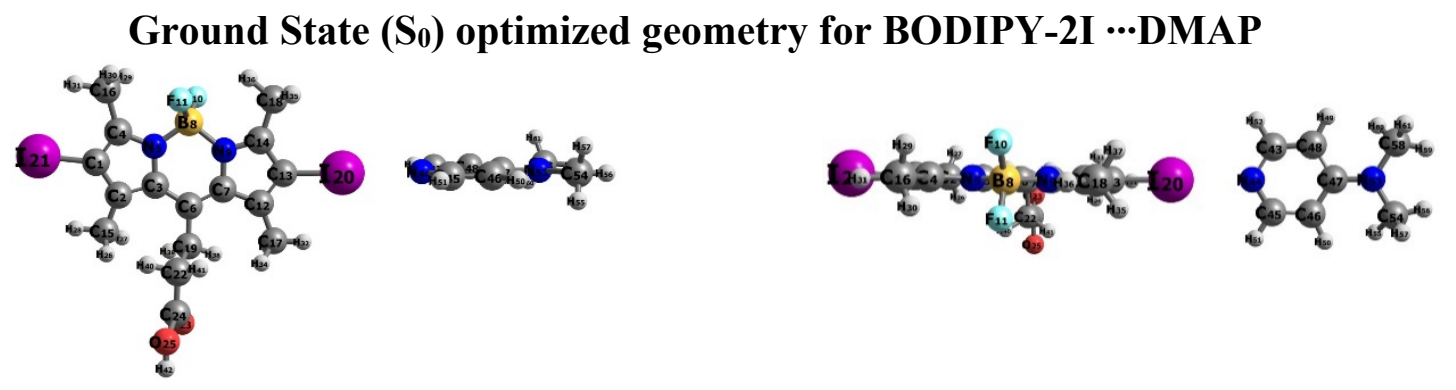

\begin{tabular}{|c|c|c|c|c|}
\hline \multirow{2}{*}{$\begin{array}{l}\text { Center } \\
\text { Number }\end{array}$} & Atomic & \multirow{2}{*}{$\begin{array}{r}\text { Atomic } \\
\text { Type }\end{array}$} & \multicolumn{2}{|c|}{ Coordinates (Angstrom } \\
\hline & Numbe & & X $\quad Y$ & Z \\
\hline 1 & 6 & 5.479101 & -0.646755 & -0.114180 \\
\hline 2 & 6 & 4.774899 & 0.532051 & -0.368242 \\
\hline 3 & 6 & 3.393505 & 0.188333 & -0.228850 \\
\hline 4 & 6 & 4.566398 & -1.680399 & 0.172284 \\
\hline 5 & 7 & 3.323719 & -1.168203 & 0.097077 \\
\hline 6 & 6 & 2.210475 & 0.949909 & -0.365938 \\
\hline 7 & 6 & 0.949722 & 0.358596 & -0.209971 \\
\hline 8 & 5 & 2.023081 & -1.975556 & 0.348224 \\
\hline 9 & 7 & 0.836982 & -1.001207 & 0.113518 \\
\hline 10 & 9 & 1.946729 & -3.051428 & -0.547750 \\
\hline 11 & 9 & 2.000201 & -2.453270 & 1.667816 \\
\hline 12 & 6 & -0.386479 & 0.884718 & -0.322323 \\
\hline 13 & 6 & -1.243964 & -0.176546 & -0.060721 \\
\hline 14 & 6 & -0.460693 & -1.326908 & 0.207633 \\
\hline 15 & 6 & 5.411182 & 1.838485 & -0.734825 \\
\hline 16 & 6 & 4.835382 & -3.106881 & 0.506620 \\
\hline 17 & 6 & -0.842461 & 2.268615 & -0.673155 \\
\hline 18 & 6 & -0.954181 & -2.691402 & 0.543538 \\
\hline 19 & 6 & 2.312528 & 2.432410 & -0.637269 \\
\hline
\end{tabular}




$\begin{array}{rrrrrc}20 & 53 & 0 & -3.359452 & -0.170085 & -0.056386 \\ 21 & 53 & 0 & 7.561984 & -0.886116 & -0.149590 \\ 22 & 6 & 0 & 2.393675 & 3.240802 & 0.668053 \\ 23 & 8 & 0 & 2.565223 & 5.267878 & -0.652361 \\ 24 & 6 & 0 & 2.514246 & 4.726880 & 0.423712 \\ 25 & 8 & 0 & 2.562574 & 5.415333 & 1.590636 \\ 26 & 1 & 0 & 5.123827 & 2.653029 & -0.066565 \\ 27 & 1 & 0 & 5.163922 & 2.143681 & -1.756250 \\ 28 & 1 & 0 & 6.495718 & 1.741934 & -0.681647 \\ 29 & 1 & 0 & 4.433374 & -3.764770 & -0.268335 \\ 30 & 1 & 0 & 4.345954 & -3.379811 & 1.444037 \\ 31 & 1 & 0 & 5.907039 & -3.277835 & 0.596197 \\ 32 & 1 & 0 & -1.929204 & 2.319119 & -0.603133 \\ 33 & 1 & 0 & -0.569959 & 2.543412 & -1.697018 \\ 34 & 1 & 0 & -0.434813 & 3.031234 & -0.005563 \\ 35 & 1 & 0 & -1.622784 & -2.641981 & 1.407696 \\ 36 & 1 & 0 & -0.139040 & -3.376233 & 0.759217 \\ 37 & 1 & 0 & -1.542395 & -3.089290 & -0.289257 \\ 38 & 1 & 0 & 1.459915 & 2.773222 & -1.215792 \\ 39 & 1 & 0 & 3.184356 & 2.648532 & -1.246832 \\ 40 & 1 & 0 & 3.246799 & 2.928489 & 1.278243 \\ 41 & 1 & 0 & 1.514858 & 3.070098 & 1.297176 \\ 42 & 1 & 0 & 2.641772 & 6.355458 & 1.368212 \\ 43 & 6 & 0 & -6.915276 & -0.442169 & -1.157993 \\ 44 & 7 & 0 & -6.208940 & -0.182466 & -0.050601 \\ 45 & 6 & 0 & -6.918069 & 0.064764 & 1.057809 \\ 46 & 6 & 0 & -8.301625 & 0.070376 & 1.118189 \\ 47 & 6 & 0 & -9.051353 & -0.194592 & -0.051417 \\ 48 & 6 & 0 & -8.298673 & -0.463767 & -1.218151 \\ 49 & 1 & 0 & -8.777088 & -0.689013 & -2.160592 \\ 50 & 1 & 0 & -8.782432 & 0.276853 & 2.063704 \\ 51 & 1 & 0 & -6.341706 & 0.269574 & 1.955761 \\ 52 & 1 & 0 & -6.336626 & -0.647567 & -2.054325 \\ 53 & 7 & 0 & -10.421645 & -0.188454 & -0.054554 \\ 54 & 6 & 0 & -11.153320 & 0.001308 & 1.190187 \\ 55 & 1 & 0 & -10.895219 & 0.955251 & 1.660707 \\ 56 & 1 & 0 & -12.220615 & 0.014093 & 0.976949 \\ 57 & 1 & 0 & -10.957893 & -0.802711 & 1.910937 \\ 58 & 6 & 0 & -11.150193 & -0.558649 & -1.259953 \\ 59 & 1 & 0 & -12.217986 & -0.454534 & -1.076281 \\ 60 & 1 & 0 & -10.889952 & 0.096014 & -2.097606 \\ 61 & 1 & 0 & -10.953917 & -1.595993 & -1.559122 \\ -------------------------------------------------------\end{array}$




\section{References}

1. $\quad$ Lim, S. H.; Thivierge, C.; Nowak-Sliwinska, P.; Han, J.; van den Bergh, H.; Wagnieres, G.; Burgess, K.; Lee, H. B. In vitro and in vivo photocytotoxicity of boron dipyrromethene derivatives for photodynamic therapy. $J$. Med. Chem. 2010, 53 (7), 2865-74.

2. $\quad$ Lee, Y.; Das, S.; Malamakal, R. M.; Meloni, S.; Chenoweth, D. M.; Anna, J. M. Ultrafast Solvation Dynamics and Vibrational Coherences of Halogenated Boron-Dipyrromethene Derivatives Revealed through TwoDimensional Electronic Spectroscopy. J. Am. Chem. Soc. 2017, 139 (41), 14733-14742.

3. $\quad$ Chauhan, V.; Bowlan, P.; Cohen, J.; Trebino, R. Single-diffraction-grating and grism pulse compressors. $J$. Opt. Soc. Am. B 2010, 27 (4), 619-624.

4. DeLong, K. W.; Trebino, R.; Hunter, J.; White, W. E. Frequency-resolved optical gating with the use of second-harmonic generation. J. Opt. Soc. Am. B 1994, 11 (11), 2206-2215.

5. $\quad$ Fork, R. L.; Martinez, O. E.; Gordon, J. P. Negative dispersion using pairs of prisms. Opt. Lett. 1984, 9 (5), $150-152$.

6. $\quad$ Cavallo, G.; Metrangolo, P.; Milani, R.; Pilati, T.; Priimagi, A.; Resnati, G.; Terraneo, G. The Halogen Bond. Chem. Rev. 2016, 116 (4), 2478-601.

7. $\quad$ Frisch, M. J.; Trucks, G. W.; Schlegel, H. B.; Scuseria, G. E.; Robb, M. A.; Cheeseman, J. R.; Scalmani, G.; Barone, V.; Mennucci, B.; Petersson, G. A.; Nakatsuji, H.; Caricato, M.; Li, X.; Hratchian, H. P.; Izmaylov, A. F.; Bloino, J.; Zheng, G.; Sonnenberg, J. L.; Hada, M.; Ehara, M.; Toyota, K.; Fukuda, R.; Hasegawa, J.; Ishida, M.; Nakajima, T.; Honda, Y.; Kitao, O.; Nakai, H.; Vreven, T.; Montgomery Jr, J. A.; Peralta, J. E.; Ogliaro, F.; Bearpark, M. J.; Heyd, J.; Brothers, E. N.; Kudin, K. N.; Staroverov, V. N.; Kobayashi, R.; Normand, J.; Raghavachari, K.; Rendell, A. P.; Burant, J. C.; Iyengar, S. S.; Tomasi, J.; Cossi, M.; Rega, N.; Millam, N. J.; Klene, M.; Knox, J. E.; Cross, J. B.; Bakken, V.; Adamo, C.; Jaramillo, J.; Gomperts, R.; Stratmann, R. E.; Yazyev, O.; Austin, A. J.; Cammi, R.; Pomelli, C.; Ochterski, J. W.; Martin, R. L.; Morokuma, K.; Zakrzewski, V. G.; Voth, G. A.; Salvador, P.; Dannenberg, J. J.; Dapprich, S.; Daniels, A. D.; Farkas, Ö.; Foresman, J. B.; Ortiz, J. V.; Cioslowski, J.; Fox, D. J. Gaussian 09, Gaussian, Inc.: Wallingford, CT, USA, 2009.

8. van Stokkum, I. H.; Larsen, D. S.; van Grondelle, R. Global and target analysis of time-resolved spectra. Biochim. Biophys. Acta 2004, 1657 (2-3), 82-104.

9. $\quad$ Sabatini, R. P.; McCormick, T. M.; Lazarides, T.; Wilson, K. C.; Eisenberg, R.; McCamant, D. W. Intersystem Crossing in Halogenated Bodipy Chromophores Used for Solar Hydrogen Production. The Journal of Physical Chemistry Letters 2011, 2 (3), 223-227.

10. Frisch, M. J.; Trucks, G. W.; Schlegel, H. B.; Scuseria, G. E.; Robb, M. A.; Cheeseman, J. R.; Scalmani, G.; Barone, V.; Petersson, G. A.; Nakatsuji, H.; Li, X.; Caricato, M.; Marenich, A. V.; Bloino, J.; Janesko, B. G.; Gomperts, R.; Mennucci, B.; Hratchian, H. P.; Ortiz, J. V.; Izmaylov, A. F.; Sonnenberg, J. L.; Williams; Ding, F.; Lipparini, F.; Egidi, F.; Goings, J.; Peng, B.; Petrone, A.; Henderson, T.; Ranasinghe, D.; Zakrzewski, V. G.; Gao, J.; Rega, N.; Zheng, G.; Liang, W.; Hada, M.; Ehara, M.; Toyota, K.; Fukuda, R.; Hasegawa, J.; Ishida, M.; Nakajima, T.; Honda, Y.; Kitao, O.; Nakai, H.; Vreven, T.; Throssell, K.; Montgomery Jr., J. A.; Peralta, J. E.; Ogliaro, F.; Bearpark, M. J.; Heyd, J. J.; Brothers, E. N.; Kudin, K. N.; Staroverov, V. N.; Keith, T. A.; Kobayashi, R.; Normand, J.; Raghavachari, K.; Rendell, A. P.; Burant, J. C.; Iyengar, S. S.; Tomasi, J.; Cossi, M.; Millam, J. M.; Klene, M.; Adamo, C.; Cammi, R.; Ochterski, J. W.; Martin, R. L.; Morokuma, K.; Farkas, O.; Foresman, J. B.; Fox, D. J. Gaussian 16 Rev. C.01, Wallingford, CT, 2016.

11. Feller, D. The role of databases in support of computational chemistry calculations. J. Comput. Chem. 1996, 17, 1571-1586.

12. Glukhovtsev, M. N.; Pross, A.; McGrath, M. P.; Radom, L. Extension of Gaussian-2 (G2) theory to bromine- and iodine-containing molecules: Use of effective core potentials. J. Chem. Phys. 1995, 103, 1878-1885. 13. Pritchard, B. P.; Altarawy, D.; Didier, B.; Gibsom, T. D.; Windus, T. L. A New Basis Set Exchange: An Open, Up-to-date Resource for the Molecular Sciences Community. J. Chem. Inf. Model. 2019, XXX, XXX.

14. Schuchardt, K. L.; Didier, B. T.; Elsethagen, T.; Sun, L.; Gurumoorthi, V.; Chase, J.; Li, J.; Windus, T. L. Basis Set Exchange: A Community Database for Computational Sciences. J. Chem. Inf. Model. 2007, 47, 10451052.

15. Gao, X.; Bai, S.; Fazzi, D.; Niehaus, T.; Barbatti, M.; Thiel, W. Evaluation of Spin-Orbit Couplings with Linear-Response Time-Dependent Density Functional Methods. J. Chem. Theory. Comput. 2017, 13 (2), 515-524. 16. Ang, S. J.; Chwee, T. S.; Wong, M. W. Does Halogen Bonding Promote Intersystem Crossing and Phosphorescence in Benzaldehyde? J. Phys. Chem. C 2018, 122 (23), 12441-12447. 